\title{
Welfare and Environment in Rural Uganda: Results from a Small-Area Estimation Approach
}

Paul Okiira Okwi', Johannes G. Hoogeveen ${ }^{2}$, Thomas Emwanu ${ }^{3}$, Vincent Linderhof ${ }^{4}$ and John Begumana ${ }^{5}$

\section{Summary}

This study combines census, survey and bio-physical data to generate spatially disaggregated poverty/biomass information for rural Uganda. It makes a methodological contribution to small area welfare estimation by exploring how the inclusion of bio-physical information improves small area welfare estimates. By combining the generated poverty estimates with national biophysical data, this study explores the correlation between poverty (welfare) and natural resource degradation at a level of geographic detail that has not been feasible previously. The precision of the resulting estimates of poverty have improved by the inclusion of bio-physical information and the poverty estimates appear to be more robust, as the standard errors show a decline in some cases by up to 40 percent. The coefficient of variation, that is, the ratio of the standard error and the point estimate decline in general as well. Overall, we conclude that the estimates of the poverty measures are more robust when biophysical information is taken into account. Part of the output from this study are maps showing poverty and biomass overlays for Uganda. These maps can be used as a planning tool and for targeting purposes.

\section{Key words}

Poverty, land use, rural, geo-referenced information, poverty maps, welfare measurement.

\section{Résumé}

Cette étude combine des données du recensement, d'enquêtes et données biophysiques pour produire des informations spatiales de pauvreté/biomasse désagrégées pour le milieu rural en Ouganda. Elle est une contribution méthodologique à l'estimation du bien-être dans les petites unités géographiques en explorant la façon dont l'inclusion des informations biophysiques améliore les estimations du bien-être dans

1: Paul Okwi, International Livestock Research Institute, ILRI, Nairobi, Kenya,

2: Johannes Hoogeveen, World Bank

3: Thomas Emwanu, Uganda Bureau of Statistics (UBOS),

4: Vincent Linderhof, Institute for Environmental Studies IVM, Free University, Amsterdam

5: John Begumana, National Forest Authority (NFA), Uganda 
les petites unités géographiques. En combinant les estimations de pauvreté avec les données nationales biophysiques, cette étude examine la corrélation entre la pauvreté (bien-être) et la dégradation des ressources naturelles à un niveau de détail géographique qui n'était pas possible auparavant. On note une amélioration de la précision des estimations de pauvreté obtenues par l'inclusion des informations biophysiques. Les estimations de pauvreté semblent être plus robustes car les erreurs types ont diminué dans certains cas de 40\%. Le coefficient de variation c'est à dire le rapport de l'erreur type par l'estimation ponctuelle a en général aussi diminué. En conclusion, les estimations de pauvreté, sont dans l'ensemble plus robustes quand les informations biophysiques sont prises en compte. Une partie des résultats de cette étude est constituée de cartes présentant des superpositions de pauvreté et de biomasse en Ouganda. Ces cartes peuvent être utilisées comme des outils de planification et de ciblage d'objectifs.

\section{Mots clés}

Pauvreté, utilisation des terres, information géo-référencée, cartes de pauvreté, mesure de bien-être

\section{Introduction}

Attaining sustainable use of bio-physical resources and sustainable growth in agriculture are important for Uganda because the economy is agriculture-based and nearly 90 percent of its 25 million people live in rural areas. Ugandan policymakers, having few resources at their disposal, must make critical decisions concerning the type of land use patterns that will prevail in future and also at the same time alleviate poverty. Unfortunately, information about poverty and land use is often incompatible. For instance, spatially disaggregated biophysical information is available but disaggregated poverty information is not. As a result, decisions are often made in an information vacuum and there is limited understanding of the dynamic processes linking poverty and land use patterns.

For both researchers and policy makers alike, various questions need to be answered. Where are the poor located? What is the state of the natural environment? What is the relation between the location of the poor and the state of the natural environment? What role do initial environmental conditions play in poverty reduction and what is the relevant level of policy intervention: regional, district, county or sub-county level? To answer these, rather basic, questions, high resolution comparable wel- 
fare and biophysical data are required. To date such information has not been available and none of the research questions formulated above could be addressed.

Recent research on poverty and the environment is either based on case study approaches or on cross-country studies. The former is unrepresentative, the latter is clouded with data incomparability problems [see Atkinson and Brandolini (1999) on the problems associated with use of the Deininger and Squire data set]. Other numerous studies have only looked at the theoretical link between poverty and environmental degradation (Ambler 1999, Barbier, 2000 and Roe, 1998). These studies show that the relative strength of links between poverty and environment may be very context-specific (Chomitz, 1999, Ekbom and Bojo, 1999). By providing comparable welfare and biophysical information for many data points, the proposed data base solves these problems. However, though some studies such as Fujii (2005) have incorporated environmental data into there estimation procedure using small area estimation techniques, biophysical information has not been linked to welfare information in Uganda as yet.

For poverty, data below the regional level are often not available. However, Hentschel, Lanjouw, Lanjouw and Poggi (1998) developed an approach to examine the geographic distribution of poverty by combining sample survey information with census data. This approach is elaborated in Elbers, Lanjouw and Lanjouw - ELL, (2003). Their approach generates welfare estimates at low levels of spatial disaggregation, and additionally, it estimates standard errors for the poverty estimates. For Uganda this approach was taken up and the results show comparable welfare estimates are feasible for rural counties for both 1991 and 1999 (Okwi et al. 2003; Hoogeveen et al. 2003). These estimates only rely on census and household survey data and do not use the available biophysical information. The ELL approach leads to high precision maps and is more robust than the more conventional approaches.

This paper builds on an existing effort to generate small area welfare estimates and combines spatially disaggregated poverty and biophysical data for 1991. We use the detailed information provided in the 1992/93 Integrated Household Survey (IHS) and combine it with the 1991 Population and Housing Census and the 1990-93 biomass data to analyse the links between poverty and bio-physical information at a more disaggregated level. This study has a spatial dimension because environmental problems are inherently geographical. These estimates are based on household per capita expenditure as a measure of welfare. In the first step, we use data from the survey of 1992/93 to estimate the relationship between poverty (measured) by household expenditure and other indicators of welfare (including household eco- 
nomic and demographic characteristics, district and regional dummies) and biomass data. In the second step, we use the values from the first stage regression for each stratum to get poverty estimates at lower levels including district, county and subcounty. In the third step, we develop poverty-biomass maps (overlays) to show the relationship between poverty and biophysical data.

Such a combination of information is valuable to policy makers who continue to struggle with the twin objectives of alleviating poverty in the short run and preserving the natural resource base in the long run ${ }^{6}$. This information is also valuable for research analysts who want to better understand the environmental-poverty nexus. From the analysis conducted in this study, we have been able to produce sets of maps (overlays) locating the poor in Uganda using an integrated database that combines census, survey and biomass information. This paper also refines the methodology of small area estimation by including biomass variables and other spatial/ environmental information in the first stage regressions for poverty mapping and considers how this improves the accuracy of the poverty/biomass maps for Uganda. Indeed, the first stage regressions results (R-square) improved on average by 2 percentage points over all the rural strata after including biomass data and the point estimates (standard errors) also improved at all levels. The small area estimates are then used to explore several dimensions of poverty and natural resource relationship in rural Uganda.

Following this introduction, this paper is divided into five sections. Section 2 provides an overview of the Ugandan country setting, providing a discussion of the patterns of poverty, natural resource use and the current policy framework. Section 3 describes the data and methods that form the basis for the research reported in this paper. It also provides an overview of the three stage empirical model that underpins the analysis of the data, drawing exclusively on the existing literature on small area estimation techniques. The results are presented and discussed in section 4, while the last section concludes and discusses the broader implications of the research.

\section{Poverty and Natural Resources in Uganda}

For many years, the Government of Uganda has been committed to poverty reduction and environmental protection. Government strategies are summarized in the

6: Personal communication Muhumuza, F., Economic Policy Research Centre; and members of the National Biomass Study, Ministry of Water Lands and environment; and National Environment Management Authority. 
Poverty Eradication Action Plan (PEAP) and implemented by the Poverty Monitoring and Analysis Unit of the Ministry of Finance, Planning and Economic Development, and the National Environment Management Authority (NEMA). With respect to poverty reduction, the Government has been quite successful although Uganda remains among the poorest countries in the world. For instance, during the 1990s poverty in Uganda almost halved from 56\% in 1992 to 35\% in 1999/2000. At the same time Uganda has faced a significant change in its landscape. Reliable figures are hard to come by but the Forest Department (2002) shows that forest cover in Uganda is shrinking at a rate of 55,000 ha per year. This has raised concern about the future supply of fuel wood, other forest products and environmental services. Many of these changes are believed to be linked to conversion of woodlands to agricultural land.

\subsection{Poverty in Uganda}

The results from different studies on poverty and inequality (Appleton 1999, 2001, Okwi et al. 2000, UPPAP 2000) in Uganda have wide ranging conclusions and are not easy to compare because either the poverty lines used were not always constant or due to other methodological differences. However, there is little correspondence of results across the studies. The studies based on survey data collected by Uganda Bureau of Statistics (UBOS) show some similarity while the other studies have some contrasting findings. Estimates of the prevalence of poverty range from 66 percent to 44 percent in 1997. Recent results from Ssewanyana and Appleton (2003) show that poverty has risen to 39 percent and inequality has remained more or less the same at Gini of 0.38 in 2002/03. All the studies clearly show that rural areas suffer from higher prevalence of poverty and inequality than do the urban areas. This situation holds even after adjusting for the cost of living differentials. This is not a surprising finding given that in many other developing countries like Kenya and Tanzania, the situation is the same. However, there may be some bias, in favour of overestimating rural relative to urban poverty in all the studies. The reason is that income and expenditure are more accurately measured in urban areas and systematic under 
measurement of these variables in rural areas is possible (UBOS, 2002). Without a concerted effort to measure all income and expenditure accurately, the degree of overestimation of rural inequality and poverty cannot be accurately known. Despite this bias, the studies universally conclude that the prevalence, depth and severity of poverty are greater in rural Uganda. Table 2.1 presents poverty estimates in Uganda between 1992 and 1999.

Table 1: Poverty estimates for Uganda, 1992-1999

\begin{tabular}{|c|c|c|c|c|c|c|c|c|c|}
\hline \multirow[t]{2}{*}{ Domain } & \multicolumn{3}{|c|}{$\begin{array}{l}\text { Poverty incidence } \\
\qquad \text { FGT(0) }\end{array}$} & \multicolumn{3}{|c|}{$\begin{array}{l}\text { Poverty gap } \\
\text { FGT(1) }\end{array}$} & \multicolumn{3}{|c|}{ FGT(2) } \\
\hline & 1992 & 1999 & 2002 & 1992 & 1999 & 2002 & 1992 & 1999 & 2002 \\
\hline Central rural & $54.3(2.2)$ & $\begin{array}{l}25.7 \\
(1.4)\end{array}$ & 27.6 & $\begin{array}{l}18.7 \\
(1.2)\end{array}$ & $5.9(0.4)$ & 6.9 & $8.8(0.7)$ & $\begin{array}{c}2.0 \\
(0.2)\end{array}$ & 2.49 \\
\hline East rural & $60.6(2.3)$ & $\begin{array}{l}38.4 \\
(1.6)\end{array}$ & 48.3 & $\begin{array}{l}23.0 \\
(1.3)\end{array}$ & $\begin{array}{l}10.5 \\
(0.6)\end{array}$ & 14.9 & $11.4(0.8)$ & $\begin{array}{c}4.2 \\
(0.3)\end{array}$ & 6.28 \\
\hline North rural & $73.0(2.9)$ & $\begin{array}{l}67.7 \\
(3.8)\end{array}$ & 34.3 & $\begin{array}{l}29.0 \\
(2.0)\end{array}$ & $\begin{array}{l}26.4 \\
(2.9)\end{array}$ & 4.8 & $14.8(1.3)$ & $\begin{array}{l}13.3 \\
(2.0)\end{array}$ & 3.39 \\
\hline West rural & $54.3(2.4)$ & $\begin{array}{l}29.5 \\
(1.9)\end{array}$ & 65.0 & $\begin{array}{l}19.2 \\
(1.3)\end{array}$ & $7.0(0.6)$ & 24.3 & $9.3(0.8)$ & $\begin{array}{c}2.4 \\
(0.2)\end{array}$ & 11.88 \\
\hline
\end{tabular}

Notes: the 1992 estimates are derived from the Integrated Household Survey (IHS). The 1999 estimates are from the Uganda National Household Survey (UNHS) and 2002/03 from UNHS. Standard errors are in parentheses.

On average, between 1998-2002 (Table 2) Uganda registered a GDP growth rate of 6.1 percent (UBOS, 2003). Previously, the country had experienced GDP growth rates of about 7.2 percent (between 1991-1997) but the slack in GDP growth start- 
ed in the fiscal year 1999/2000 due to a fall in world coffee prices, droughts, civil wars and the war in the Democratic Republic of Congo (DRC), increases in pests and diseases and a rise in world prices of oil (UBOS, 2001). These shocks affected the expansion of the productive sectors and the economy's position with the rest of the world. Infant mortality stood at 88 per 1000 live births while maternal mortality was 504 per 100,000 live births in 2001.

\section{Table 2 Uganda: Key economic and social indicators}

\begin{tabular}{|l|c|c|}
\hline Indicator & Year or period & Index \\
\hline Surface area ('000 of Km squared) & 2002 & $\mathbf{2 4 1 . 0}$ \\
\hline Population (millions) & 2002 & $\mathbf{2 4 . 7}$ \\
\hline Population (Annual growth rate) & $1991-2002$ & $\mathbf{3 . 4 \%}$ \\
\hline GNP per capita (US \$) & 2002 & $\mathbf{3 2 0}$ \\
\hline GDP annual growth rate & $1998-2002$ & $\mathbf{6 . 1 \%}$ \\
\hline Agriculture (percent share in GDP) & 2002 & $\mathbf{4 4 . 0 \%}$ \\
\hline Agriculture (percent annual growth rate) & $1998-2002$ & $\mathbf{3 . 7 \%}$ \\
\hline Deforestation (percentage of total area ) & $1990-1995$ & $\mathbf{0 . 9 \%}$ \\
\hline Labour force (millions) & 1999 & $\mathbf{1 1 . 0}$ \\
\hline Average annual growth of labour force (percent) & $1990-1999$ & $\mathbf{2 . 6 \%}$ \\
\hline Infant mortality (per 1,000 live births) & 2001 & $\mathbf{8 8}$ \\
\hline Maternal mortality ratio (per 100,000 live births) & 2001 & $\mathbf{5 0 4}$ \\
\hline Life expectancy (number of years) & 2002 & $\mathbf{4 8 . 1}$ \\
\hline \multicolumn{1}{|l|}{ Male } & & $\mathbf{4 5 . 7}$ \\
\hline Female & 2001 & $\mathbf{6 . 7 \%}$ \\
\hline Total fertility rate & 2001 & $\mathbf{6 - 7 \%}$ \\
\hline HIV/AIDS prevalence & 2001 & $\mathbf{3 9 \%}$ \\
\hline Nutrition (stunting) & & \\
\hline
\end{tabular}

Source: World Bank, World Development Report (2002) and UBOS (2001, 2003).

\subsection{The state of the natural environment in Uganda}

Uganda occupies an area of 241,038 square kilometers of which 43,941 square kilometers is open water and swamps and the rest is land area. The population of Uganda was estimated at 24.7 million in 2002, with an annual growth rate of 3.4 percent during 1991-2002 and a population density of 126 people per square kilo- 
meter (UBOS, 2002). The settlement patterns in the rural areas vary, depending on a number of factors: areas with consistently good rains, good soils, and free from disease agents, have high and rising population densities. Areas with less rain, less fertile soils, and which are not free from disease agents, have low population densities. Security is another major factor, which determines settlement pattern in Uganda: for instance, the serious security problems in the northern region since the 1980's are one reason for its low population density.

Besides the other uses like pasture, farmland constitutes the biggest proportion of land use (35\%) in Uganda, see Figure 1. The average landholding size in Uganda ranges from 0.4 to 3 hectares per typical household of seven persons. This landholding size has been declining over the years due to population pressure (UBOS, 2002). The climate of Uganda is more of the "equatorial" type. The area has two wet seasons, with intervening short dry seasons of one to three months. The vegetation is typically savannah, though there are some forests on the mountain ranges, and riparian vegetation in river valleys. There is a wide range of savannah woodland. This savannah is usually interspersed by perennial grasses (Department of Forestry, 2002).

Figure 1: Relative Land Cover Distribution

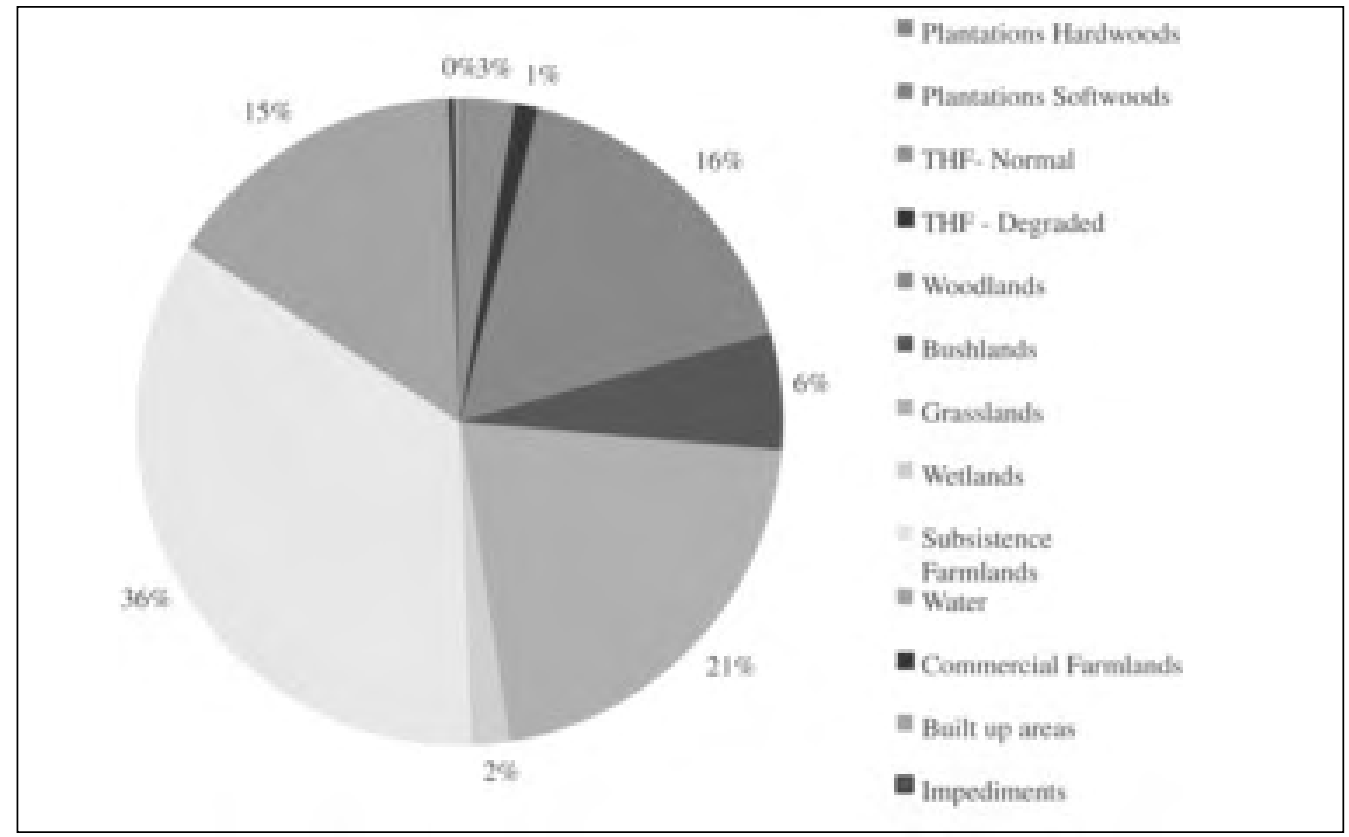

Source: National Biomass Study, Uganda. 
Figure A1 in Appendix A shows how the land use covers is divided over Uganda.

\subsection{The institutional and policy framework}

Since 1987, the government of Uganda has been implementing an economic reform program supported by a large number of donors like the World Bank, International Monetary Fund (IMF) and United States Agency for International Development (USAID). This reform program aims to promote fiscal and economic management, develop the human capital through investment in education, health and other social services, reform the regulatory framework and improve incentives to the private sector. The result of this program has been realized through macroeconomic stability now seen, and the continued growth of GDP, on average about 5 percent per annum since 1987. Some studies have found that policy reforms included in the current economic and liberalization and adjustment efforts may increase the pressure on forests (Jones and O'Neill 1995, Angelsen and Kaimowitz, 1999). For instance, Kant and Redantz, (1997), show a positive correlation between external indebtedness and deforestation. However, some of these empirical studies are based on poor quality data; the analytical models make very simplistic assumptions about government objectives and policy formulation that limit their relevance.

There are two major players in the use and conservation of natural resources, the individuals/households and the government institutions. In Uganda, the government has more power in the conservation and use of natural resources. Government plays two main roles in the management of natural resources. They often own them and influence their allocation by setting the legal framework through policies that affect incentives to which other resource users respond. The natural environment is managed by the Department of Forestry in conjunction with the National Environment Management Authority (NEMA). Tropical forests are almost invariably publicly owned, and the infrastructure of water resources, as well, is often developed and owned by the public sector. It is important to note that the property rights are often unclear to the communities around them. The reason for government management of the natural resources is that the government is best placed to pursue multiple objectives - environmental protection, economic growth, regional development and support of indigenous people and cultural heritage. But the government ownership and management in the pursuit of such public objectives need to be effective if they are to overcome the incentives for private gain. 
In Uganda, government stewardship of resources has shown a mixed record of successes and failures (NEMA, 2002). The failures are basically bureaucratic. The institutions are often inefficient and overstaffed with unqualified personnel. The other related problem is that under-priced natural resources put additional pressure on resource management agencies. By creating opportunities for corruption and personal gain, under-pricing makes the agencies vulnerable to influence from the politically powerful. For instance, forestry departments come under pressure to provide low-cost materials to industries and allow encroachment on gazetted areas so as to serve politically important areas and people. Meanwhile, essential tasks with little political appeal, such as maintenance and regeneration are overlooked.

\section{Data and Methods}

\subsection{Data}

The central element in this study is the availability of survey, census and biomass information. For purposes of this project, we used census data for 1991 and sample survey data from 1992 (Integrated Household Survey) to derive welfare estimates and maps. The surveys are multi-purpose household and community surveys, in the same vein as the World Bank's Living Standard Measurement Study (LSMS) surveys and were designed and implemented by the Uganda Bureau of Statistics (UBOS). The Integrated Household Survey (IHS) used a stratified sample of 10,000 households in both rural and urban areas. The survey questionnaire collected information on household and demographic characteristics, education, assets, employment, income and expenditure (Uganda Bureau of Statistics, 1992/93). The sample was designed to be nationally representative, as well as representative of the four regions divided into rural and urban strata. In this study, we only use the 4 rural strata as for these strata we can include bio-physical information in the update of welfare estimates (using a sample of households present in the IHS).

The second data source is the 1991 census which was conducted by the same institution (UBOS) and was meant to cover the entire population in both rural and urban areas. Two forms of questionnaires were used, a short and long form. The short form of the questionnaire covered mainly information on household members and education and was administered to all households in the country. The long form of the questionnaire covered housing characteristics and access to basic utilities and was administered to only 10 percent of rural areas (UBOS, 1991). The 10 percent is 
representative at district level. Although the census did not collect information on income and expenditure, it provides information on a number of characteristics likely to be correlates of poverty. The census and survey data have several common household variables such as household size, composition, education, housing characteristics, access to utilities and location of residences. In this method, it is important that the survey and census are almost covering the same period. The main assumption of the method is that the parameters estimated from the survey data are almost equally applicable to the period covered by the census.

To capture the environment aspects, we use geo-referenced information from the National Biomass Study of the Ministry of Water, Lands and the Environment. The project developed its own classification system based on a combination of land cover and land uses. This information covers changes in land cover such as broadleaved tree plantation or woodlots, coniferous plantations, tropical high forests (normal and depleted/encroached), woodlands, grasslands, wetlands, water resources and land use such as subsistence and commercial farmland, and changes in landscape among other aspects. The biomass indicators vary at the cluster level. To capture some of these variables, the proportion of the parish (lowest administrative unit in the country) under each land use type was used. For example, to capture wetlands the proportion of the parish that is covered by wetlands was used. Similarly, for subsistence farmland the proportion of the parish under subsistence farms was used. This criterion was used for all the other land use types.

In the National Biomass Study (NBS) project, the country was split into 9,000 plots with 3 sample plots at each intersection. However, due to influences of population density and agro-ecological zones on land cover and tree growth, some adjustments were made on the overall total sample plots. Topographic maps, land cover maps $(1: 50,000)$ and Global Positioning System (GPS) were used to locate the field plots on the ground. There were four categories of data capture and processing i.e. mapping (spatial and its attributes), biomass survey (filed plot measurements), monitoring of biomass and land cover change. This information details the woody biomass stock for each plot and it can be used to assess the relationship between tree cover and poverty. The data is extremely rich in bio-physical factors and also includes the distribution of infrastructure like markets, roads, schools and others. Besides, the GIS format of the data allows us to explore the possibilities of merging the data sets using GIS variables.

In addition to the land uses derived from the GIS information, we have also distance to road indicator as well. For each geographical area (districts, counties, sub-counties or even parishes), we have three different types of roads (main road, tarmac road 
and track) calculated the total amount of area within the range or buffer of this particular type of road. We calculated five buffer zones ranging from 5 kilometres down to 1 kilometre. Figures A2 to A4 in Appendix A present the buffer zones for main roads, tarmac roads and tracks respectively. Note that as the buffer zones narrowed down from 5 to 1 kilometre, the percentages of total land area decrease. In particular, in North Uganda particularly, the areas are less close to any type of road than in other parts of Uganda.

\subsection{Overview of the analysis}

In Uganda, the availability of high-resolution datasets is a strong foundation for us to produce and use poverty-biomass maps. Although several approaches have been developed to design poverty maps, there has been less effort to develop poverty/biomass maps. The Ugandan situation is unique because two decades ago, the country was faced with deteriorating economic, social and environmental conditions. However today, the social and economic trends have been greatly reversed, but it is not clear what the implications of these changes are for the natural resource base. The approach we use to link these problems uses statistical estimation techniques (small area estimation) to overcome the typical limitations in the geographic coverage of household welfare that surveys provide and the lack of welfare indicators in the census data, and includes biomass information to assess these changes.

Our approach to the analysis of the links between poverty and biomass using maps begins with the construction of a poverty map. We adopt the approach developed by Elbers, Lanjouw \& Lanjouw (2003). First, we select variables based on comparable variables found in the survey and census data sets. The variables are derived from the comparable questions in the questionnaires. This is done because the empirical modelling of household consumption is limited by the set of variables that is common in the two data sets. A test is done to compare the means for the survey and census variables and the variables that pass the significance test are considered for the regression analysis. Close examination of the data shows that several variables that appear to be the same in the two data sets were really quite different. Reasons for these differences could be attributed to the fact that probably the two exercises measured distinctively different things for these variables or that the survey was simply not representative of population for these variables.

A logical next step is to make the connection between welfare and biophysical information. However, obtaining information on biomass use for administrative units is 
not straightforward, because of confidentiality, different data formats, the intricacies of geo-analysis and because environmental conditions do not follow administrative boundaries. There have been attempts to link poverty to other socio-economic factors that do not follow administrative boundaries (e.g. ILRI 2002), suggesting that combining poverty with other information (in this case on livestock) is key for a convincing integrated framework to address poverty issues for pastoralist populations.

Once the census and biophysical datasets are integrated, ELL welfare estimates can be improved (see for instance. Mistiaen et al. 2002 for Madagascar). The preliminary poverty estimates for rural Uganda control for spatial autocorrelation solely by relying on Population Sampling Unit (PSU) means calculated from the census. By controlling for biophysical characteristics of the estimation procedure, the efficiency of the derived poverty estimates may be improved, leading to more precise estimates and enhancing the level of spatial disaggregation that is attainable.

In the regression analysis, we use household survey data to estimate per capita expenditure as a function of a variety of household characteristics. This estimation takes the form:

$$
\ln y_{c h}=\chi_{c h} \beta+\eta_{c}(Z)+\epsilon_{c h}
$$

Where $y_{c h}$ is the log of per capita consumption expenditure of household $h$ residing in cluster $c, X_{c h}$ are the household characteristics that are observable in both the survey and census data sets, and $\beta$ is a coefficient vector. In our household survey, the clustering is done at regional (disaggregated into rural and urban) areas. The error term is composed of two parts. On the one hand, $\eta_{\mathrm{C}}(Z)$ applies to all households within a given cluster (location effect), which depends on the biomass conditions $Z$. On the other hand, $\epsilon_{\mathrm{ch}}$ is household specific component of the error term (heteroscedasticity). These two error components are uncorrelated with one another and independent of the regressors. This specification of the error term allows for heteroscedasticity of the household specific error component. It also allows for the possibility of spatial autocorrelation. That is, location specific effects that are common to all households within a cluster.

To reduce the magnitude of the unexplained location specific component, we estimate a separate model to explain the cluster specific error terms. As regressors, cluster means of the household specific variables are obtained from the census at enumeration area level and merged into the survey data set. This is a common procedure in poverty mapping. It amounts to explaining spatial autocorrelation between 
factors common to a household in a given PSU. To the extent that households attend the same school, make use of the same source of fuel wood, or water and have similar access to markets, this procedure is likely to go a long way in explaining spatial autocorrelation. Yet, various rather obvious determinants of spatial autocorrelation cannot be obtained from the census. Population and tree density, soil type and quality, access to infrastructure are examples of such information. By building an integrated dataset with census and biomass information, we are able to include such bio-physical information in explaining spatial autocorrelation. We estimate equation 1 taking into consideration the location and heteroscedasticity component of the disturbance term. Survey weights are included in some of the regressions depending on the Hausman test (see Deaton, 1997) results for whether the regressions should be weighted or unweighted.

Separate regressions were estimated for 1991 for each of the 4 rural strata of the survey data set. For 1999 only one model was estimated. We consider the set of variables that passed the test (zero stage) selection process and the final selection of variables are determined by a stepwise procedure.

The next step (second stage) is to predict out of sample and apply the survey equation to the census data. Since we are using household level census data, the combination produces estimates of per capita expenditure for each household. We simulate the level of consumption for each household based on Elbers et al. (2003).

\section{Empirical Implementation}

\subsection{Zero Stage: Selection of Variables}

The first step is known as the "zero stage". In this stage, we compare variables from the survey and census, and we select potential ones, which are later used in the regression models described in the methods above. Principally, the idea is to obtain variables from the household survey, which are comparable to those in the census. The initial step is to look at the question in both the survey and census. This should provide a clue as to whether the responses should provide similar information. However, it is not usually obvious that identical questions will yield similar responses for several reasons. For instance, the way the question was asked, the local language translation of the question, the ordering of the questions or even variations in interpretation of questions may provide major differences in the responses. To verify 
that the questions yielded similar answers, we conduct an assessment to determine whether the variables are statistically similarly distributed over the households in the survey and census. This assessment is done for each of the four strata and the comparison is done at regional level (four regions focusing only on rural strata).

After a comparison of wording, coding and instructions in the enumerator manual, we constructed a more disaggregated total of 167 potentially identical variables, which sometimes involved interactions among some variables. ${ }^{7}$ Then, using statistical criteria, we compare the stratum level means of the variables to assess the level of similarity. We do this by testing whether the survey mean for a particular variable lies within the 95 percent confidence interval around the census mean for the same variable. A third and final step is to do a comparison of the variables across the two categories of strata (rural and urban) to assess the level of uniformity in comparability. The selection of variables used in the first stage was based on criteria, which picked all continuous variables found to be comparable. For the dummy variables, we tested whether the census and survey means were identical ${ }^{8}$.

\subsection{Re-weighting}

Despite being identified as potentially identical, household size did not pass the distribution comparison test. It differed consistently between the census and the survey in that small households are underrepresented in the survey. For instance, in Central rural the census mean for one-person households is 18.4 percent but the corresponding figure in the survey is 16.3 percent. As household size is crucial when deriving per capita welfare estimates, it was less of an option to drop it from the common set of variables. And fed by the suspicion that small households are underrepresented because of non-response and improper replacement (Hoogeveen, 2003) we decided to reweigh the survey.

The re-weighting strategy followed is known as post-stratification adjustment (Lessler and Kalsbeek, 1992). It ensures that the weighted relative frequency distribution among mutually exclusive and exhaustive categories in the survey corresponds precisely to the relative distribution among those same categories in the census. In total 13 different household size categories were distinguished, reflecting

7: More detailed information on the variables and the zero-stage comparison can be obtained from Okwi et al. (2005), which is the supplementary report of this study. The definitions of variables are listed in

Chapter 2, while Chapter 3 presents the results of the zero-stage comparison.

8: For a full list of zero-stage comparisons, we refer to Chapter 3 of Okwi et al. (2005). 
households of size 1-12 with category 13 reflecting households of size 13 and over, and re-weighting was done at the stratum level. A danger of re-weighting along one dimension, household size in this case, is that survey variables that were representative using the 'old' weights become non-representative once the weights have been adjusted to control for unrepresentativeness in other dimensions. On the other hand, if the adjustment corrects for a genuine sampling error, the comparability between the survey and the census should improve in all dimensions. As a check on the appropriateness of re-weighting, we compared the set of variables that were considered identical on the basis of wording, coding and enumerator instructions and how many passed the survey-census means comparison test before and after re-weighting. Re-weighting increased the number of variables that passed this test in all rural strata considerably, while improving the fit for household size related variables.

\subsection{First Stage}

The first stage estimation is conducted using the household survey data, census and biomass data. Since we are analysing only rural data, the household survey is stratified into four sub-regions, and we estimate four different models. At this stage, we construct more interaction terms from the selected census, survey and biomass variables, then use a stepwise regression approach in SAS to select the variables which provide the best explanatory power to the log per capita expenditure. As is the case with other similar studies, we use a significance level criterion with no ceiling on the number of variables to be selected. The significance level used for selecting variables was 5 percent.

To develop an accurate model of household consumption, we consider the model specified in equation 1. In this model, the error component is attributable to location and household specific effects. The presence of these errors makes our welfare estimates less precise. Since unexplained location effects reduce the precision of our poverty estimates, the first goal is to explain the variation in consumption due to location as far as possible with the choice and construction of explanatory variables. We attempt to reduce the magnitude of the location effect in four ways.

i. We include in our specification district dummies and their interaction terms with key household level variables (household size, level of education, age of head of household). All districts in Uganda are represented in the survey.

ii. We calculate means at the enumeration area (EA) level in the census of 
household characteristics such as household size and composition, and the gender, age and average level of education of household heads. We then merge these EA means into the household survey and consider their interactions with household characteristics obtained from the survey for inclusion in the household regression specification.

iii. For the information collected from the long form questionnaire, (for 10\% of the rural households and representative at the district level) on housing characteristics, use of fuel, access to water sources, etc. we calculate district means and interact these with household characteristics.

iv. Finally, we include in our specification biomass variables and their interaction terms with key household level variables. The biomass variables include information on distance to roads, proportion of land under grassland, woodland, water, farmland and forests.

So far in the household model, cluster level means and biomass data that interacted with household characteristics are included. To further select location variables we determine the common component in the household specific error terms and regress this on enumeration area and district means. We then select a limited number ( 5 at most) of variables that best explain the variation in the cluster fixed effects estimates. The number of explanatory variables is limited so as to avoid over-fitting. The selected location variables are included in the household regression model after which a combined model is estimated comprising of household specific and location variables. A Hausman test described in Deaton (1997) is used to determine whether to estimate our final regression models for each stratum with household weights. We re-estimate the regressions in equation 1 , but after adding weights to the selected explanatory variables.

We model the idiosyncratic part of the disturbance by choosing variables from the set of potential variables selected from the census and survey, their squares and interactions. To select a subset of these variables, we use $\epsilon_{c h}^{2}$ as the dependent variable in the stepwise regression and choose not more than 10 variables that best explain the variation in the household specific part of the residual.

Finally, we determine the distribution of $\eta_{c}$ and $\epsilon_{c h}$ using the cluster residuals $\eta_{c}$ and standardised household residuals: $e_{c h}^{*}=\frac{e_{c h}}{\sigma_{E, c h}}-\left[\frac{1}{H} \sum_{c h} \frac{e_{c h}}{\sigma_{E, c h}}\right]$, respectively, 
where $\mathrm{h}$ is the number of households in the survey. We use normal distributions for each of the error components. The consumption model is then re-estimated using the Generalised Least Squares (GLS) method using the variance-covariance matrix resulting from the above equation. ${ }^{9}$

Table 3 summarizes the results of the first-stage regression, and it shows that the adjusted $\mathrm{R}^{2} \mathrm{~s}$ of the models for 1991 vary from 0.35 to $0.46^{10}$, (see also Tables B1 to B4 in Appendix B for examples of regressions results). According to Table 3, inclusion of biomass information helped to raise the $R^{2} s$ by an average 2 percentage points compared to the models without them. The relatively low $R^{2} s$ in the rural areas may be attributed to at least two reasons. First, the number of variables in the census short forms is limited to mostly household composition, education and ethnic origin $^{11}$. Secondly, household composition and education only change slowly over time. The returns to agriculture are variables much dependent on rainfall, illness of family labourers, incidence of pests and diseases and prices. Again some of this variation may be captured, for instance the age of the head of household and proneness to disease are correlated, but much of the cross sectional variation attributable to any of these sources will remain unexplained and gets subsumed in the error term.

\section{Table 3: Summary Statistics of First Stage Regression Models (Rural Strata)}

\begin{tabular}{|l|l|l|l|l|}
\hline Number of observations & \multicolumn{3}{|c|}{ IHS } \\
\cline { 2 - 5 } & Central & East & North & West \\
\hline Number of observations used in regressions & 1660 & 1640 & 1368 & 1637 \\
Number of clusters $^{1}$ & 163 & 165 & 144 & 163 \\
Hausman test for weights & 1.29 & 1.04 & 1.71 & 1.84 \\
Regression weighted? & Yes & Yes & Yes & Yes \\
Adjusted $\mathrm{R}^{2}$ without location means & 0.27 & 0.32 & 0.39 & 0.31 \\
Adjusted $\mathrm{R}^{2}$ with location means no biomass & 0.31 & 0.34 & 0.44 & 0.32 \\
Adjusted $\mathrm{R}^{2}$ with location means including biomass & 0.35 & 0.36 & 0.46 & 0.34 \\
data & &
\end{tabular}

Note: In the IHS the cluster is defined by the census enumeration area. The models without location means and with location means and no biomass are derived from Okwi et al. (2003).

Despite not being high, the explanatory levels are comparable to those attained else-

9: For a description of different approaches to simulation see Elbers et al. (2001 and 2003)

10: Note that the regressions are simply association models, and therefore the parameter estimates should not be interpreted as causal effects.

11: Inclusion of all the variables from the short form and biomass data raised the $\mathrm{R}^{2}$ but not to the urban strata levels implying we still needed to use more information such as housing characteristics to improve them. 
where in Africa. For instance, in rural Madagascar the adjusted $R^{2}$ range from 0.239 to 0.460 (Mistiaen et al. 2002) and in Malawi it ranges from 0.248 to 0.448 (Machinjili and Benson, 2002). Considering that for Uganda, the long form of the questionnaire was available for only $10 \%$ of the rural households, the Ugandan R-squares seem to do relatively well.

\subsection{The link between poverty and the environment in Uganda.}

There have been attempts to link poverty to other socio-economic factors that do not follow administrative boundaries (e.g. ILRI 2002), suggesting that combining poverty with other information (in this case on livestock) is key for a convincing integrated framework to address poverty issues for pastoralist populations. For Uganda, where most households are involved in agriculture, this finding motivates our attempt to combine poverty and environmental information.

A logical next step is to make the connection between welfare and biophysical information. However, as already noted, the regression analysis presents association and not causal models. There is need, therefore, for careful interpretation of the regression results. But it is important to note that obtaining information on biomass use for administrative units is not straightforward, because of confidentiality, different data formats, the intricacies of geo-analysis and because environmental conditions do not follow administrative boundaries. We consider a number of bio-physical factors, including proximity from parish centre to nearest main, tarmac and track roads separated into 1 to 5 kilometres, proportion of the parish land under woodlots, coniferous forests, tropical high forests, degraded forests, woodlands, grasslands, papyrus (wetland), subsistence and commercial farmland, water and impediments.

The regression results presented in Tables B1 to B4 in the Appendix B suggest some spatial correlation between poverty and some bio-physical variables. The ability of these variables to improve the explanatory power of the models is interesting but different variables were selected for the different strata. A few principal variables stand out to be clear correlates of poverty. Access to roads has much explanatory association to poverty in all the four rural strata. Despite the fact that the types of roads differ between the strata, the regression results indicate a close spatial correlation with poverty. In the rural central stratum, access to main and track roads was an important variable while in north rural, access to both main and tarmac roads was important. Likewise for east rural, access to track and tarmac roads was important 
and in the west rural, tarmac and track roads are important. The spatial correlation between poverty and access to roads is evident. Although our evidence is indirect, we conclude that access to various types of roads is potentially an important issue in Uganda. By implication, any policy focused on improving access to roads will yield disproportionate benefits for the poor.

Tables B1-B4 and Tables E1-E2 in Appendices summarize the available evidence of the association between poverty and other bio-physical information. Besides access to roads, the proportion of land under woodland, subsistence and commercial farms turned out to be the most important biomass variables associated with rural poverty in central rural. Meanwhile, in the east rural, proportion of land under commercial farms, woodland and the proportion of degraded forests were important spatial variables correlated with poverty. In the north, the proportion of land under water, subsistence farmland and subsistence farmland in the wetlands were the important spatial variables. The selection of water bodies and wet farmland is probably suggestive of the fact that northern region is generally dry and access to water or wetland could be important factors in explaining poverty, given that most of Uganda's rural population depends on agriculture. For west rural, the proportion of land under woodlots and subsistence farmland has spatial relations with poverty. In addition to the selected variables, biomass variables interacted with household characteristics also proved to be important in explaining the correlation between poverty and biomass. The results from the regression analysis clearly display regional variation in spatial correlation between bio-physical and poverty information. This evidence suggests that there is strong relationship between poverty and biomass variables. We conclude that access to subsistence and commercial farmland, wetland/water, woodlands, roads and grasslands are important spatial factors correlated with poverty in Uganda.

\section{Results}

Once the census and bio-physical data sets are integrated, ELL welfare estimates can be improved (see for instance Mistiaen et al. 2002 for Madagascar). The preliminary poverty estimates for rural Uganda control for spatial autocorrelation solely by relying on PSU means calculated from the census. The second stage analyses sought to use the rural models highlight the importance of bio-physical factors in poverty estimation. First, the results of the second stage analysis are used to examine the extent to which the poverty estimates from the census and bio-physical data ${ }^{12}$ 
match the sample estimates at the level which the survey is representative (region). Secondly, we ask how far we can disaggregate our census/biophysical-based poverty estimates, when we take the survey based sampling errors to indicate acceptable levels of precision. Lastly, we focus on the ultimate goal of the analysis, namely to produce disaggregated spatial profiles of poverty and biomass. Using poverty/ biomass maps, we show how projecting poverty estimates and biomass information produces a quick and appealing way in which to convey a considerable amount of information on the spatial relationship between poverty and the natural environment to users. We use poverty and biomass overlays to show the spatial heterogeneity of poverty and the natural environment.

The results of the welfare indicators measured by the conventional Foster-GreerThorbecke measures FGT $(\alpha)$ are reported with $\alpha$-values of 0,1 and 2 reflecting respectively poverty incidence, poverty gap and the poverty gap squared. As benchmark the official monthly per capita poverty lines (in 1989 prices) are used, i.e. Uganda shillings 15,947 for rural Central, shillings 15,446 for rural East, shillings 15,610 for rural North and shillings 15,189 for rural West. Table 4 below summarizes the poverty inequality estimates based on the predictions of the combined biomass and census at the regional level and the survey based estimates. The detailed estimates for the district level are presented in the appendices. To reduce clutter, the poverty estimates for the county and sub-county are presented in form of maps.

At the stratum level, the results are reasonably close to those from the survey. Interestingly, most standard errors are lower than when no biomass data was included, in some cases by up to 40 percent. As shown in Table 4, the results show a consistent story with the survey and census-based estimates. Central rural emerges with the least level of poverty even when census/biomass data is used for prediction, while north rural remains the poorest of the four strata. When other measures of welfare such as the poverty gap ( $\mathrm{P}-1)$ and the poverty gap squared $(\mathrm{P}-2)$ are used, the comparison among the rural strata still remains consistent with the survey rankings. The inclusion of the bio-physical data improved the poverty estimates at the stratum level and lowered the census-bio-physical based standard errors consistently. This is even when some parishes in the North and West did not have corresponding biophysical data.

12: Some observations were missing in the census/biomass data therefore the populations represented may not be exactly the same as if it was census based data alone 


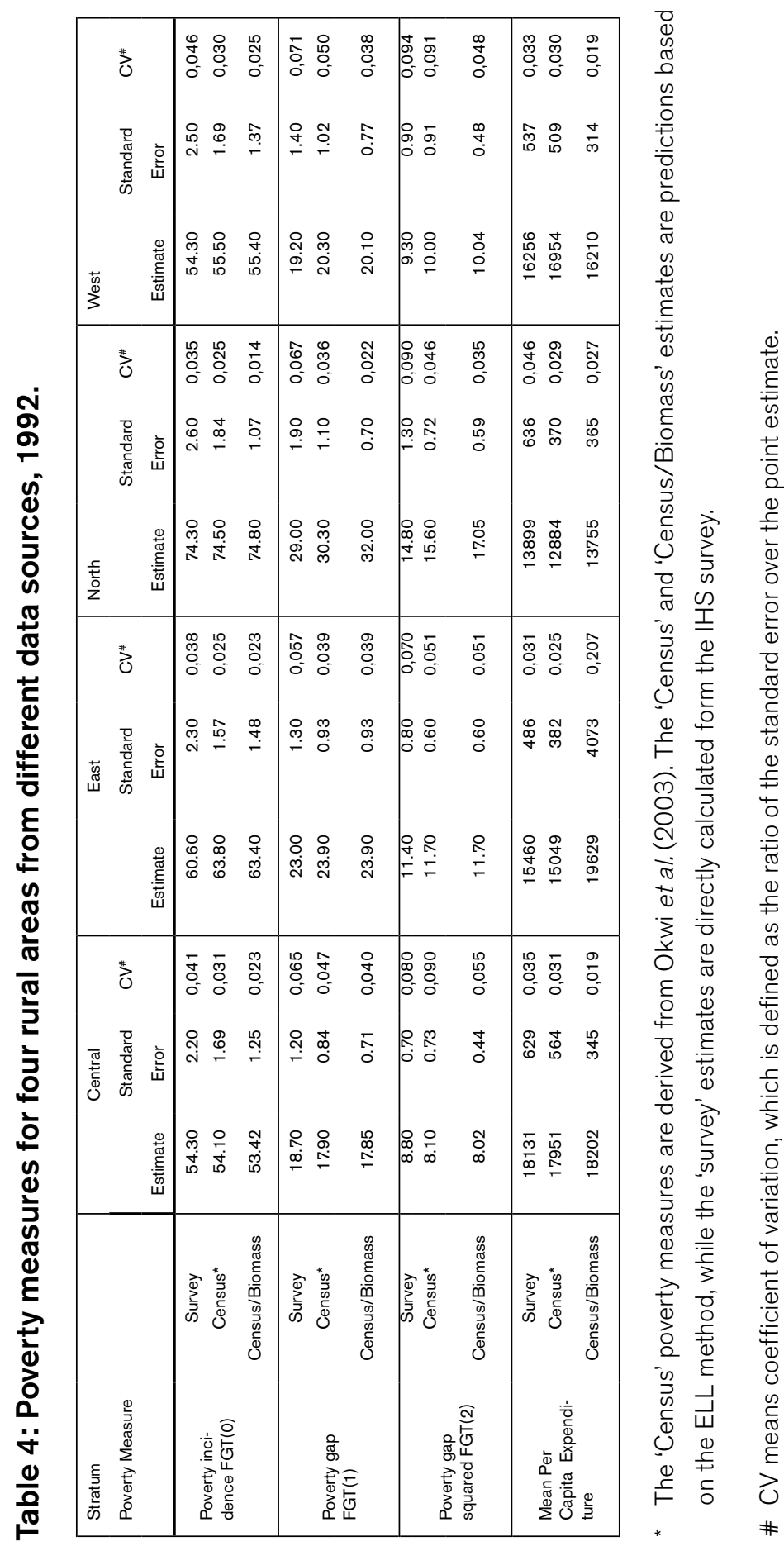


The inclusion of the bio-physical information in the small-area estimation procedures has one major effect. The level of the precision of poverty measures (standard errors) can change. Table 4 presents estimates of four poverty measures at the regional level in 1992. Poverty measures from three different sources compared. The survey-based estimates are directly calculated from the IHS database. The 'Census predicted' estimates are based on the ELL method without the use of bio-physical information (see Okwi et al., 2003), and finally, the 'Census/Biomass predicted' estimates are from the present study. In this study we focus attention on the comparison of 'Census' and 'Census/Biomass' estimates.

The level of precision of the poverty measure estimates has changed due to the inclusion of bio-physical information. In Central, all the poverty measures slightly declined while for East, all poverty measures hardly changed. Except for the poverty incidence, the level of precision of the other poverty measures improved in the northern region. The poverty estimates for West Uganda hardly changed, while the accompanying standard errors declined again suggesting improved precision of the estimates. The graphs in Appendix $F$ show the new poverty estimates and the standard errors of the present study at different aggregation levels in comparison with the 'old' results of Okwi et al. (2003).

In addition, we analyse the extent to which the inclusion of spatial features can allow our poverty estimates to be robust. There are two major ways of determining the level of disaggregation at which the error becomes too big. They both yield similar conclusions in most cases. One way to approach this is to consider the absolute level of the standard error. The other method, which is used in this study, is to calculate the coefficient of variation (CV), which is the ratio of the standard error over the point estimate for each administrative unit and compare this with the survey-based ratios.

The inclusion of biomass variables has improved the standard errors (in some cases by up to 40 percent) of our estimators at the stratum level. Finally, this section offered insights about the inclusion of bio-physical and other spatial features in poverty estimation. It demonstrated that relative improvements can be made in the estimation of welfare - with the inclusion of more explanatory spatial characteristics. That is, by controlling for bio-physical characteristics at the estimation procedure, the efficiency of the derived poverty estimates may be improved, leading to more precise estimates and enhancing the level of spatial disaggregation that is attainable. Awareness of this association, combined with well designed policies are key factors that may support poverty reduction in these areas. 
Tables C1 and C2 in Appendix C present the poverty estimates at district level. These poverty estimates show some level of heterogeneity. All the standard errors fall below the stratum level survey based ones with the exception of Kalangala district in central region. The case for Kalangala district is an interesting and expected one. First, this is a small district with a total population of 14, 218 people which is significantly less than the population of any most sub-counties and even parishes in the region. For example, in Central region, the poverty estimates range from 25 percent to 63 percent at the district and 19.6 to 74 percent at the county. In Eastern, the poverty levels range from 39.5 to 82 percent at the district level. At the county level, the observed distribution is more interesting than at the district level. In the North, Arua is the least poor district (64 percent) while Kotido is the poorest with 91 percent poor. Similarly, Western region shows significant variation in poverty levels. Whereas Masindi has about 76 percent headcount ratio, Mbarara is the least poor with only 43 percent. Generally, there is wide variation in the poverty estimates in all the strata and we cannot categorically identify one region as being the poorest as there may be pockets of wealthy areas within the poorest region. The level distributions of poverty at various levels are shown in the graphs in Appendix F.

Further, to explain the link between certain bio-physical characteristics and poverty, we use overlays presented in Appendix $\mathrm{D} .^{13}$ The overlays are simply meant to provide a visual explanation of the relationship between poverty and land-use. For example, from the overlays, we can identify the poverty hotspots and correlate them with the type of land use in the area. A clear example is that poverty is more pronounced in the Northern parts which are typically wooded and grassland areas and less pronounced in the degraded lands of all the regions. The implication of the later result is that the poor are actually using the ecological resources to improve their welfare but in the process they degrade the natural environment as well. However, a contrasting picture emerges from the grassland areas in Western and Northern regions which portray less and more poverty respectively, see also according correlation coefficients with opposite signs in the Table E1 and E2 in Appendix E. A question that emerges is why the difference? Possible explanations for the difference could be because the pastoral lands in Western Uganda have been modified by the people to produce high yielding varieties thus directly improving their welfare, while the pastoralists in the North are still held with the traditional norms of cattle rearing. The overlays generally have helped us to answer the following questions: Where are the poor? Which poor (rich) areas have similar types of land-use features? Which ar-

13: The county level estimates of the household expenditures and the head count are presented in Chapter 4 of Okwi et al. (2005). 
eas provide which type/amount of ecosystem services? How do the land-use types overlap with poverty? How does the location of poverty compare to the distribution of ecosystem services? Which areas have access to better resources and what are the benefits and costs? This information may help policymakers to design effective policies to improve the situation. For detailed maps, see the poverty and biomass maps for all strata in Appendices E.

\section{Conclusions and implications for policy}

This study combines census, survey and bio-physical data to generate spatially disaggregated poverty/biomass information for rural Uganda. It makes a methodological contribution to small area welfare estimation by exploring the inclusion of bio-physical information. By combining the generated poverty estimates with national bio-physical data, this study explores the correlation between poverty (welfare) and natural resource degradation at a level of geographic detail that has not been feasible previously. In this welfare estimation method, association relationships are used to explain welfare rather than causal relationships. However, the resulting estimates of poverty measures have improved by the inclusion of bio-physical information. In some cases the levels of poverty measures have changed. For North Uganda, the poverty gap and poverty gap squared increased compared to the estimates without bio-physical information.

By providing comparable welfare and bio-physical information for many data points, this study solves many problems faced by many previous studies. For instance, previous studies (see Atkinson and Brandolini, 1999) on poverty and the environment were based on case studies which are unrepresentative. This study presents results of a representative sample and population. Secondly, previous studies have also been cross-sectional thus raising data incomparability problems. By using data from one country and collected by the same institution, with comparable questions in the questionnaires and within a period of time less than 2 years, data incomparability problems are solved. Thirdly, this study has provided a practical analysis of the link between welfare and the environment. Other studies have only looked at the theoretical link between poverty and environmental degradation (Ambler 1999; Barbier, 2000; Roe, 1998; Chomitz, 1999; Ekbom and Bojo, 1999). This study has shown that accounting for spatial differences in welfare is key to high precision maps and explaining poverty environment relationships.

The poverty estimates appear to be more robust, as the standard errors show a decline in some cases by up to 40 percent. Moreover, the coefficient of variation, that is, 
the ratio of the standard error and the point estimate decline in general as well. Overall, we conclude that the estimates of the poverty measures are more robust when bio-physical information is taken into account. Part of the output from this study are maps showing poverty and biomass overlays for Uganda. These maps can be used as a planning tool and for targeting purposes.

In terms of policy, by implication, any policy focused on improving access to roads is directly related to the welfare of the poor. Similarly, policies focused on conservation of wetlands and forests, improvement of grasslands (mainly pasture land), and access to water could be important policy issues to consider in understanding the relationship between poverty and the environment. Given that most of Uganda's rural population depends on agriculture and the environment, and considering the spatial relationship between subsistence farming, degraded lands and poverty, the results suggest that focusing on improving production in the subsistence sector may prove important in reducing poverty and improving the biomass conditions. The results from the regression analysis clearly display regional up to county level variation in spatial correlation between bio-physical and poverty information and therefore imply region specific policy designs. Finally, in future research, with more information, the causal relationship will be analysed in more detail.

\section{References}

Ambler, J. (1999). Attacking Poverty While Improving the Environment. Towards WinWin Policy Options. Background Technical Paper Prepared for the September 1999 Forum of Ministers Meeting, under the UNDP-EC Poverty and Environment Initiative.

Appleton, S., Emwanu, T., Kagugube, J. and Muwonge, J. (1999). Changes in Poverty in Uganda, 1992-1997. Centre for the Study of African Economies, Oxford Working Paper Series, WPS 99.

Appleton, S. (2001). Poverty in Uganda, 1999/2000: Preliminary Estimates from the Uganda National Household Survey. University of Nottingham. Mimeo.

Angelsen, A. and Kaimowtz, D. (1999). Rethinking the Causes of Deforestation: Lessons from Economic Models, The World Bank Research Observer, 14(1), 73-98. 
Atkinson, A.B. and Brandolini, A. (1999). Promises and Pitfall in the Use of "Secondary" Datasets: Income Inequality in OECD Countries as Case Study, Journal of Economic Literature 39(3), 771-799.

Barbier, E. (2000). The Economic Linkages Between Rural Poverty and Land Degradation: Some Evidence from Africa, Agriculture, Ecosystems and Environment, 82, 355-370.

Besley, T. and Kanbur, R. (1993). The Principles of Targeting, In M.Lipton \& J.vander Gaag, Including the Poor, Proceedings of Symposium Organized by the World Bank and the International Food policy Research Institute (IFPRI). Regional and Sectoral Studies, Washington D.C: the World Bank

Chomitz, K. (1999). Environment Poverty Connections in Tropical Deforestation, Discussion Notes prepared for the WDR workshop on Poverty and Development. Washington DC. July 6-8.

Datt, G. and Ravallion, M. (1998). Why Have Some Indian States Done Better Than Others at Reducing Rural Poverty?, Economica, 65(257), 17-38.

Deaton, A. (1997). The Analysis of Household Surveys: A Microeconometric Approach to Development Policy. Baltimore, MD: Johns Hopkins University Press.

Demombynes, G., Elbers, C., Lanjouw, J.O, Lanjouw, P., Mistiaen, J.A. and Ozler, B. (2002). Producing an Improved Geographic Profile of Uganda: Methodology and Evidence from Three Developing Countries, Discussion Paper 2002/39, WIDER, Helsinki, Finland.

Ekbom, A. and Bojo, J. (1999). Poverty and Environment. Evidence of Links and Integration in the Country Assistance Strategy Process, World Bank. Africa Region Discussion Paper no. 4 World Bank. Washington DC.

Elbers, C., Lanjouw, J.O. and Lanjouw, P. (2002). Welfare in Villages and Towns: Microlevel Estimation of Poverty and Inequality, Policy Research Working Paper, World Bank: Washington D.C.

Elbers, C., Lanjouw, J.O and Lanjouw, P. (2003). Micro-level Estimation of Poverty and Inequality, Econometrica 71(1), 355-364. 
Forest Department. (1988). National Biomass Project Document. Kampala, Uganda

Forest Department. (1992). National Biomass Study Phase I Technical Report. Kampala, Uganda.

Forest Department. (1994). National Biomass Study Evaluation Mission Report. Kampala, Uganda.

Forest Department. (1995). National Biomass Review Mission Report. Kampala, Uganda.

Forest Department. (1996). National Biomass Study Phase III Project Document. Kampala, Uganda.

Forest Department. (2002). National Biomass Study Final Report. Kampala, Uganda.

Foster, J. Greer, J. and Thorbecke, E. (1984). A Class of Decomposable Poverty Measures, Econometrica, 52, 761-66.

Fujii, T. (2005). Micro-Level Estimation of Child Malnutrition Indicators and Its Application in Cambodia, World Bank Working Paper, WPS 3662.

Glewwe, P. (1990). Efficient Allocation of Transfers to the Poor. The Problem of Unobserved Household Income, Working Paper, 70, Living Standards Measurement study. Washington D.C: The World Bank.

Glewwe, P. and van der Gaag, J. (1990). Identifying the Poor in Developing Countries: Do Different Definitions Matter? World Development, 18, 6.

Government of Uganda. (1991). Uganda Population and Housing Census, Uganda Bureau of Statistics.

Hentchel J., Lanjouw, J., Lanjouw, P. and Poggi, J. (2000). Combining Census and Survey Data to Trace Spatial Dimensions of Poverty: A Case Study of Ecuador, World Bank Economic Review, 14,1, 147-65. Washington D.C: The World Bank.

Emwanu, T., Hoogeveen, J. G., and Okwi O.P.(2006). Updating Small Area Welfare Indicators in the Absence of a New Census, World Development, Forthcoming. 
International Livestock Research Institute (2002). Mapping Poverty and Livestock in East Africa, ILRI publications.

Jones, D.W. and O'Neill, R.V. (1995). Development Policies, Urban Unemployment, and Deforestation: The Role of Infrastructure and Tax Policy in a Two-Sector Model, Journal of Regional Science 35, 135-53.

Kant, S. and Redantz, A. (1997). An Econometric Model of Tropical Deforestation, Journal of Forestry Economics 3, 51-86.

Machinjili, C. and Benson, T. (2002). Malawi: An Atlas of Social Statistics, National Statistics office, Malawi

Minot, N. (2000). Generating Disaggregated Poverty Maps: An Application to Vietnam. World Development, 28, 2.

Mistiaen J. A., Ozler, B., Razafimanantena, T. and Razafindravonona, J. (2002). Putting "Welfare on the Map in Madagascar". The World Bank: African Region Working Paper Series, 34.

Moller, L. (2002). A Practical Guide to Developing Good Poverty Indicators. Based on Uganda's experience, Mimeo.

NEMA (2002). State of the Environment Report, National Environment Management Authority, Uganda.

Okwi, P.O., and Kaija, D. (2000). The Distribution of Welfare in Uganda. Eastern Africa Social Science Research Review, XVI, 2.

Okwi, P.O., Emwanu, T and Hoogeveen, J.G. (2003). Poverty and Inequality in Uganda: Evidence from Small Area Estimation Techniques. Unpublished Okwi, P.O., Hoogeveen, J.G., Emwanu, T. Linderhof, V.G.M. and Begumana, J. (2005). Welfare and the Environment in Rural Uganda: Facts and Figures. PREM report 2005. Institute for Environmental Studies.

Ravallion, M. and Wodon, Q. (1997). Poor areas, or only poor people? Policy Research Working Paper, 1798. Washington D.C: the World Bank. 
Roe, E. (1998). Taking Complexity Seriously. Policy Analysis, Triangulation and Sustainable Development, Kluwer Academic Publishers: Boston USA.

Uganda Bureau of Statistics. (2001). Statistical Abstract. Government of Uganda.

Uganda Bureau of Statistics. (2002). Statistical Abstract. Government of Uganda

Uganda Bureau of Statistics. (2003). Statistical Abstract. Government of Uganda

Wodon, Q. (1997). Targeting the poor using ROC curves. World Development, 25, 12.

World Bank (2002), World Development Report. New York: Oxford University Press.

\section{Appendix A: Bio-physical information for Uganda}

This appendix summarizes the bio-physical information for Uganda in 1991/1992. We have two types of biomass indicators. Firstly, we have a land use indicator, i.e. total area per land use type divided by the total area. Secondly, we have distance to road indicators, i.e. the total area within a certain distance of a particular road type divided by the total area.

In Figure A1, we use classes based on natural groupings inherent in the data. The break points are identified by picking the class breaks that best group similar values and maximize the differences between classes. The features are divided into classes whose boundaries are set where there are relatively big jumps in the data values. 
APPENDIX A

Figure A1: Land use classifications: Proportion of county area under different land use types

Plartations and woodots -deciduous and coniferous

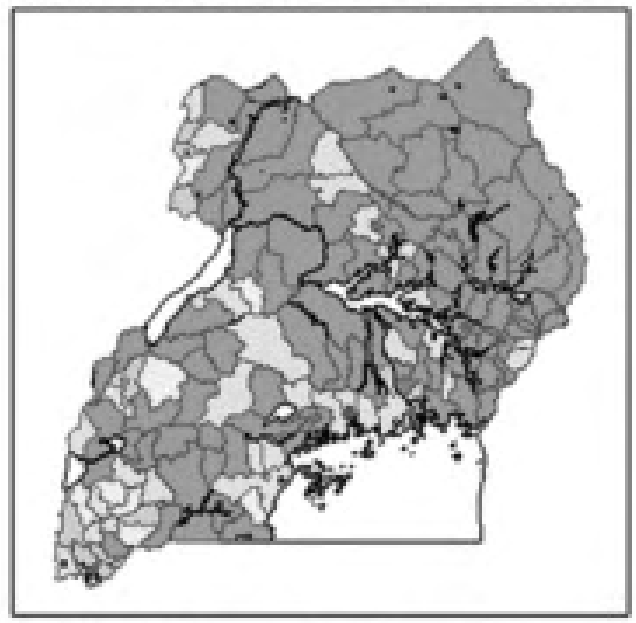

Woodlots

$\square 0.0=0.1 \%$

ए $0.1 \cdot 0.5 \%$

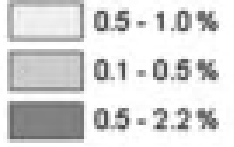

Tropical High Forest (THF) depletedenctroached
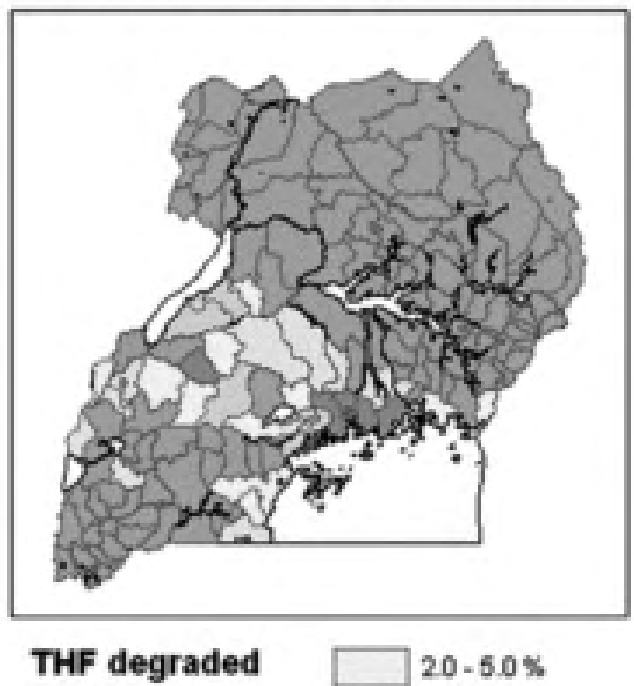

0.0-0.05 \%

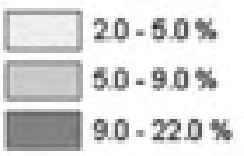

Tropical High Forest (THF) nom ally stocked

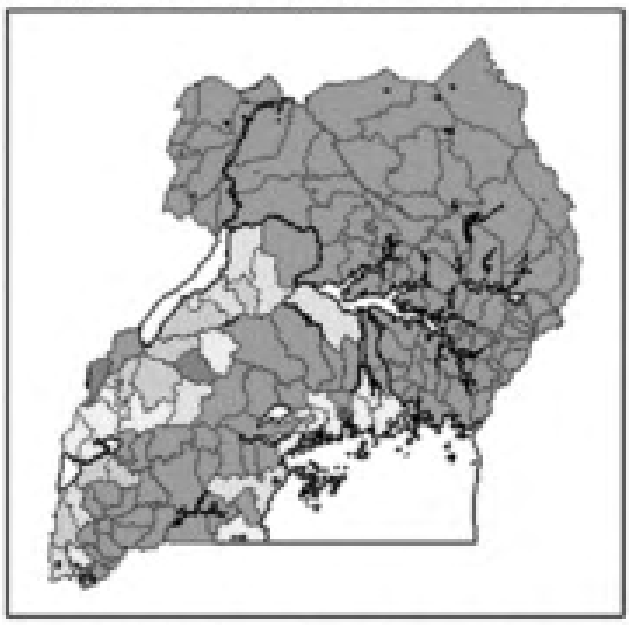

THF normal

$0.7-15.0 \%$

ए $0.0 .0 .2 \%$

$15.0-25.0 \%$

$0.2=0.7 \%$ 
Figure A1: Land use classifications: Proportion of county area under different land use types (continued)
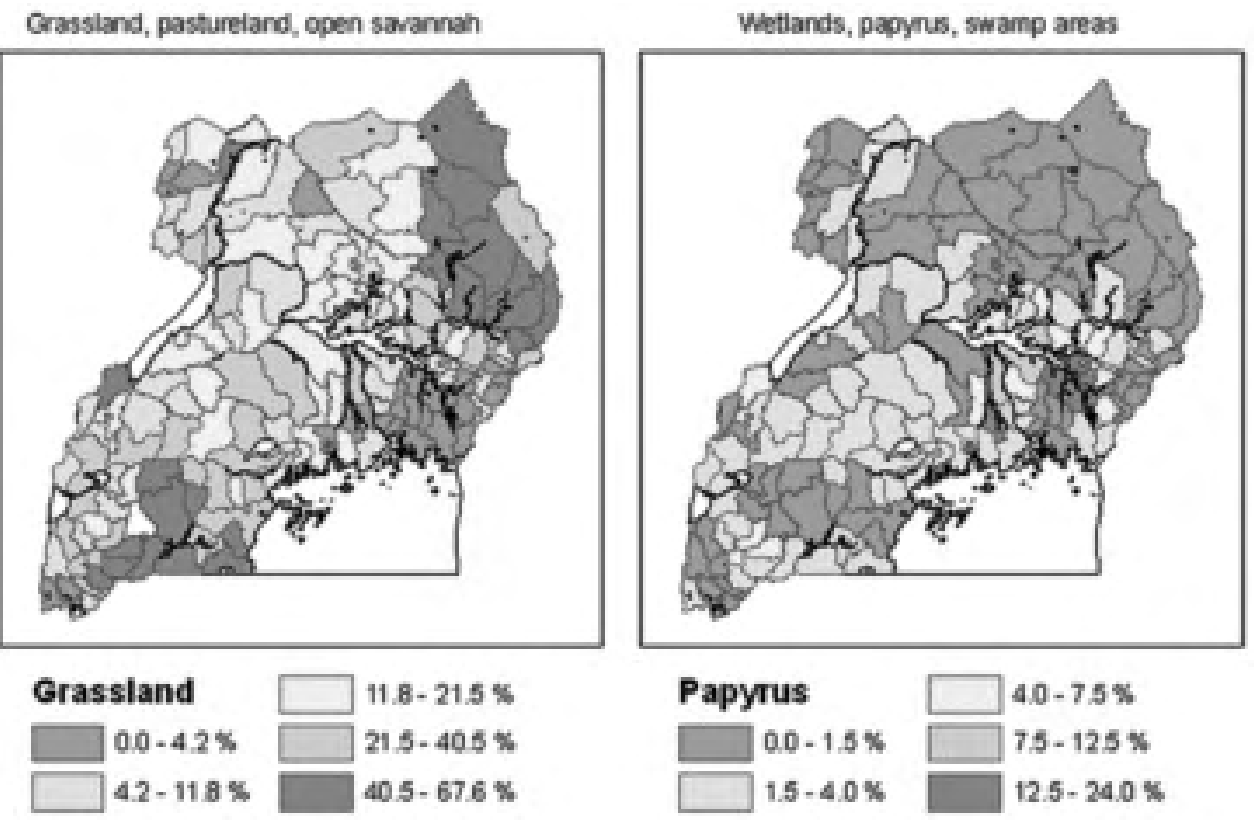

\section{Subsistence famland, mbed tarmland}
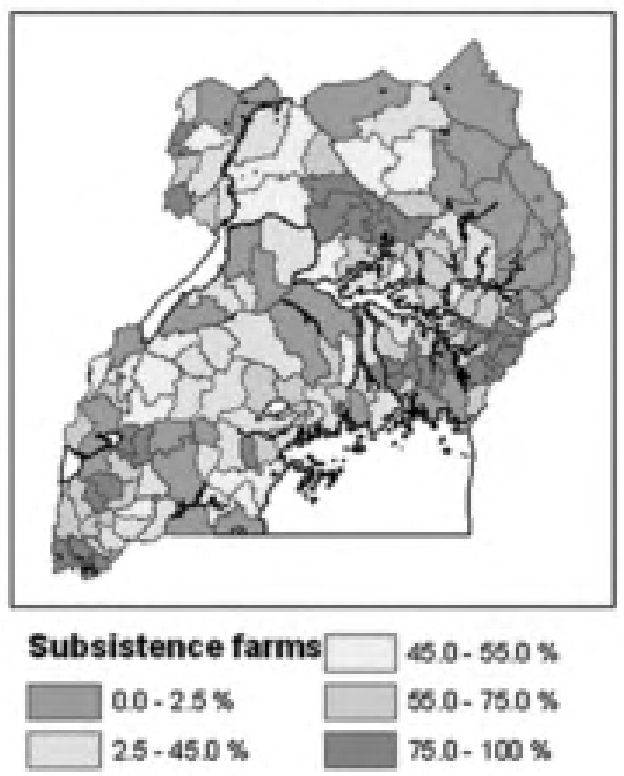

Commercial tamiand, mono-cropped, non-seasonal

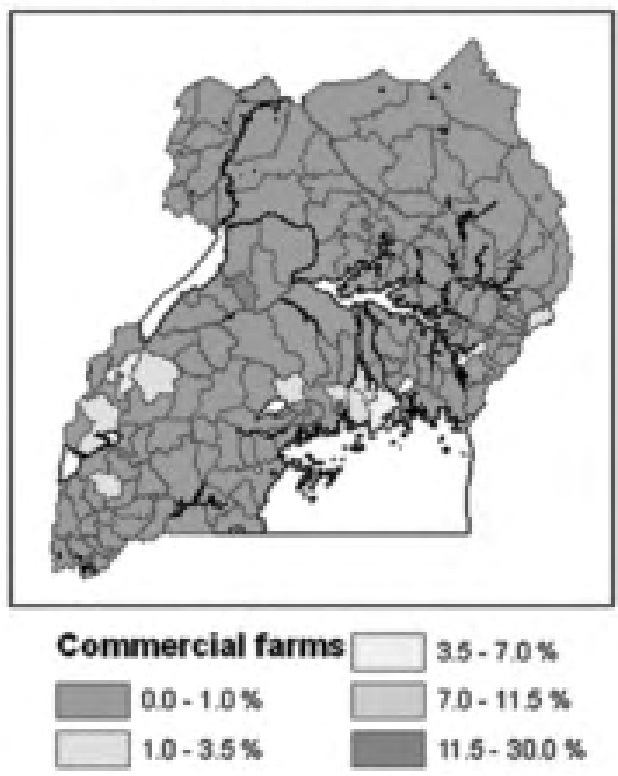


Figure A2: Main road buffers: Proportion of county area within a distance from 5 down to 1 kilometre to main roads

Area within Sian of main road

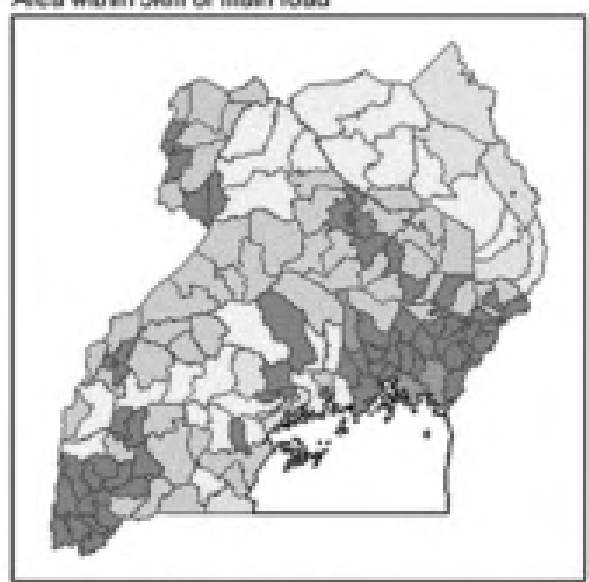

Area wivin 3km of main rogd

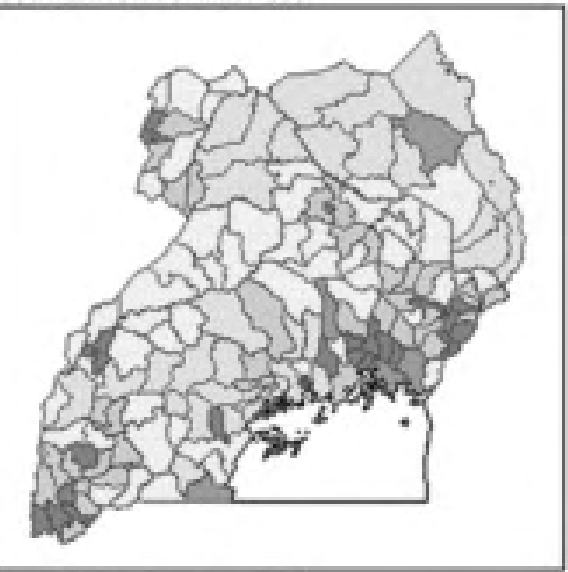

Area withn $1 \mathrm{~km}$ of main road

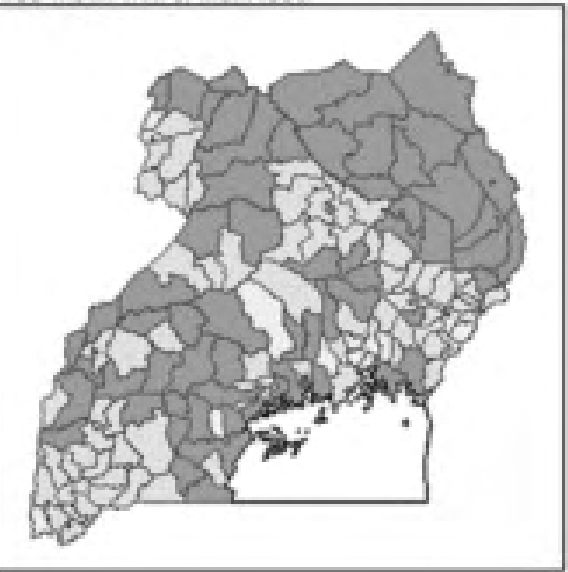

Area werin akm of main road

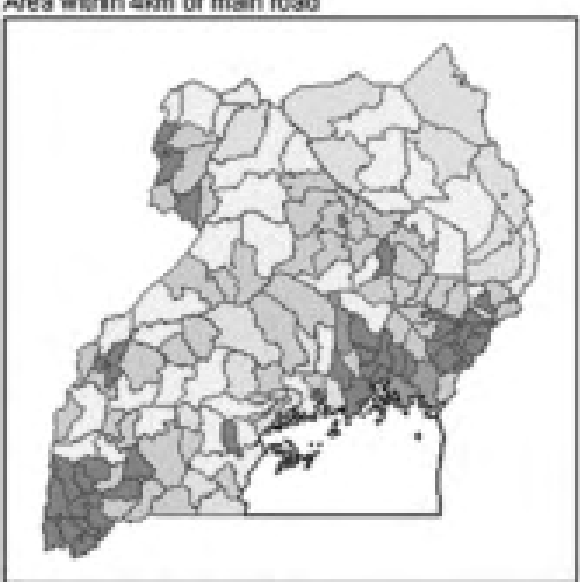

Area werin $2 \mathrm{~km}$ of main road

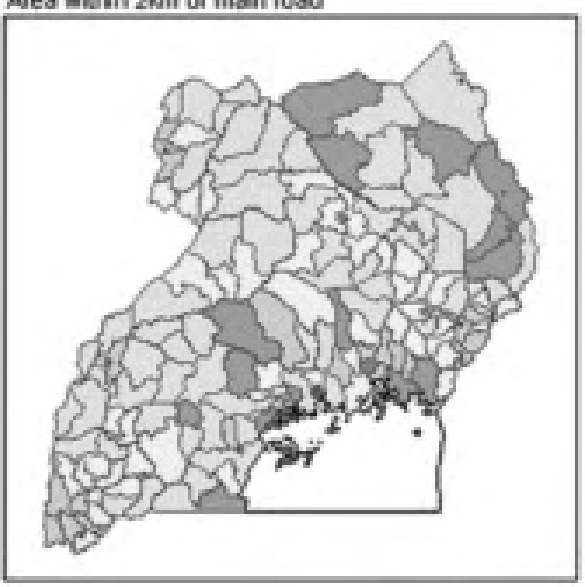

Legend

Main road butters

ए $0-20 \%$ $20-40 \%$ $40.60 \%$ $60.80 \%$ $80-100 \%$ 
Figure A3: Tarmac road buffers: Proportion of county area within a distance from 5 down to 1 kilometre to tarmac roads

Area w thin Slen of tarmac road

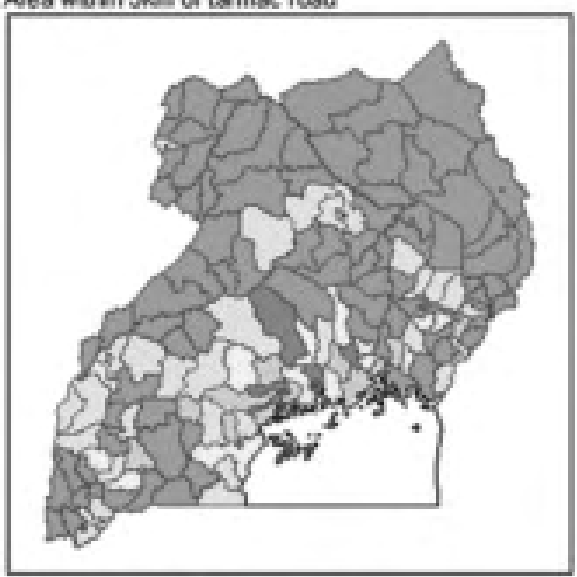

Area within 3km of tarmac rosd

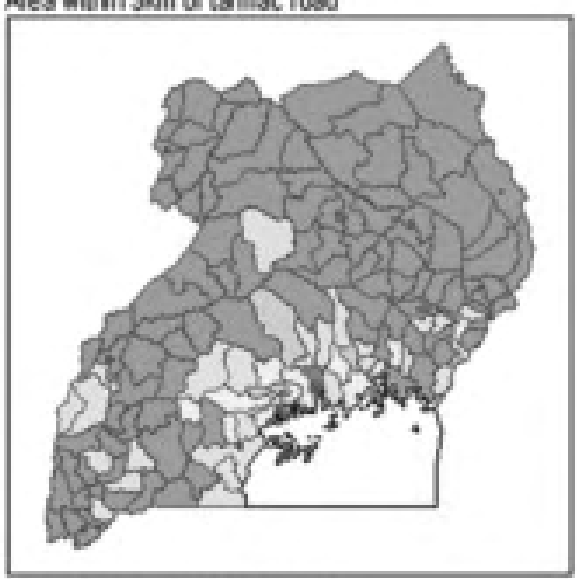

Area within $1 \mathrm{~km}$ of tarmat rosd

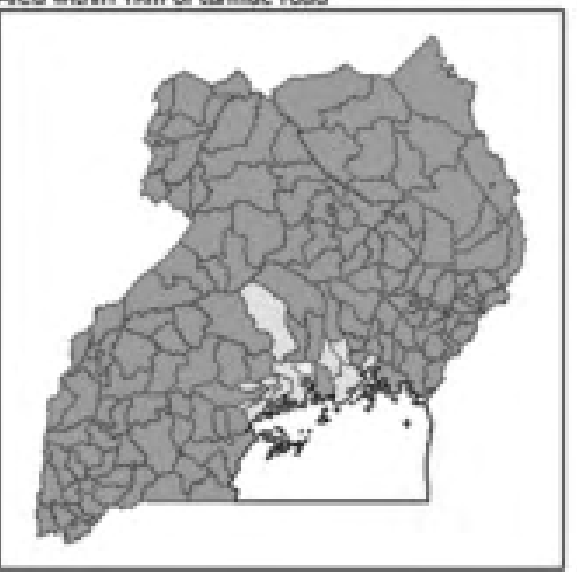

Area within $4 h m$ of tarmsc road
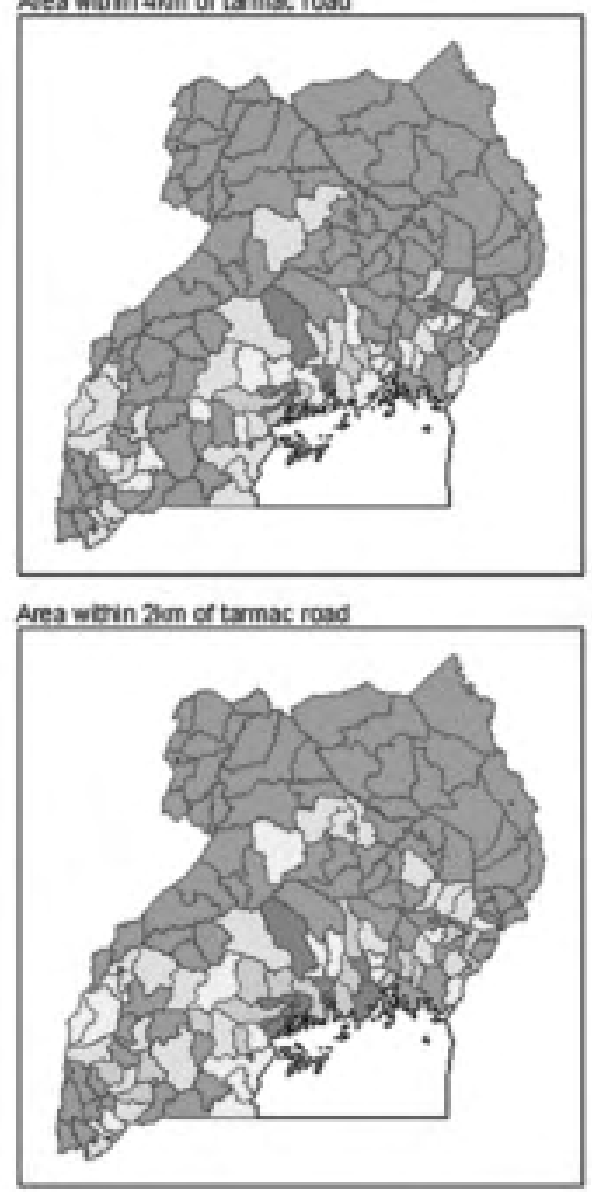

Legend

Tamac road buffers

$0.20 \%$
$20-40 \%$
$40-60 \%$
$60-80 \%$
$80-100 \%$


Figure A4: Track road buffers: Proportion of county area within a distance from 5 down to 1 kilometre to tracks

Area within Slim of track

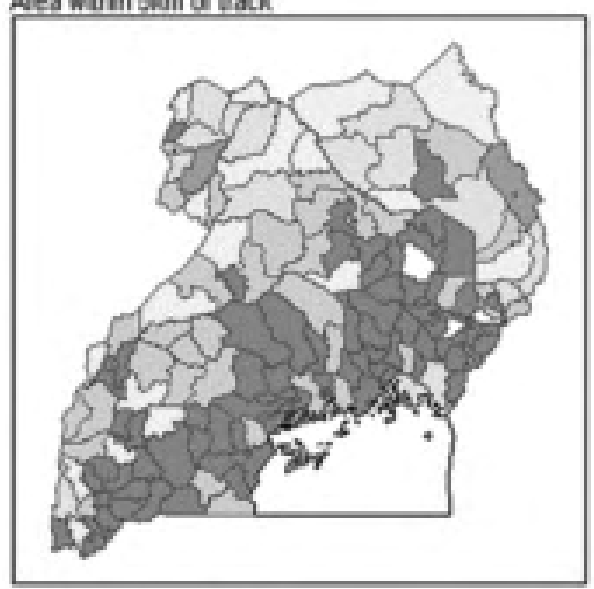

Area within $3 k$ of track

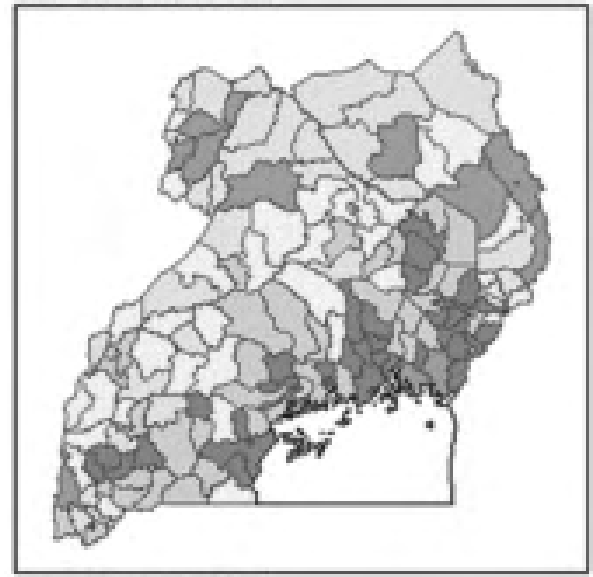

Area wittin $1 \mathrm{~km}$ of track

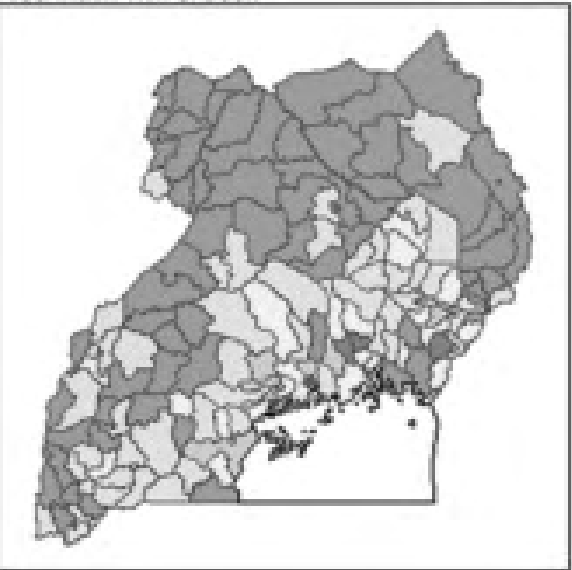

Area within Alion of track

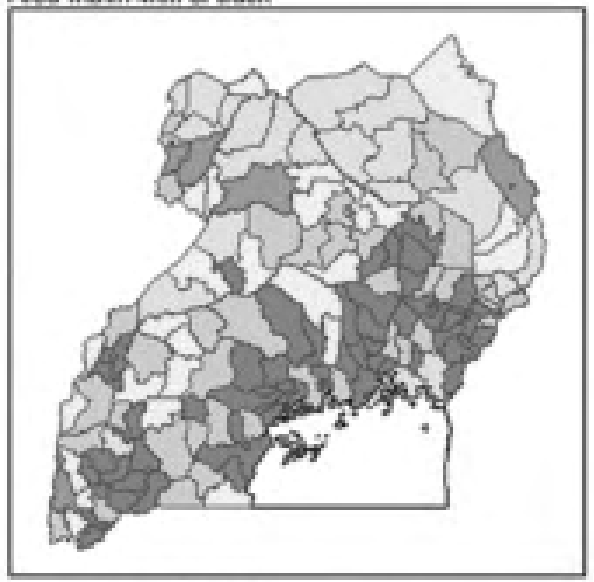

Area witrin $2 \mathrm{hm}$ of track

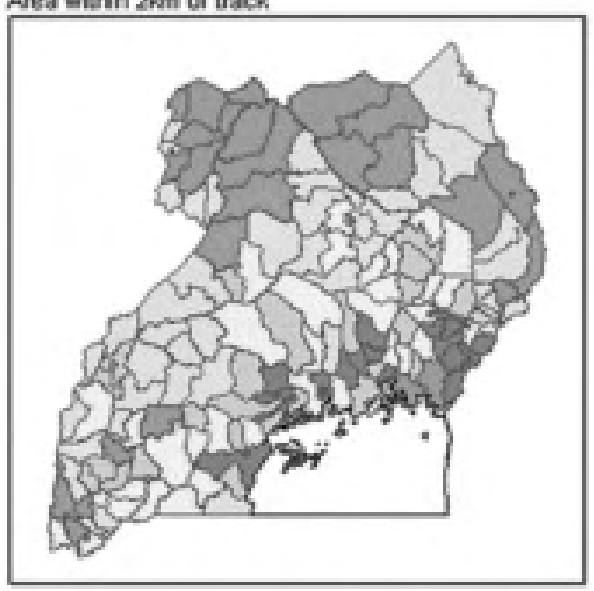

Legend

Track butters

$0.20 \%$

$20 \cdot 40 \%$ $40.60 \%$ $60.60 \%$ $80.100 \%$ 
Paul Okiira Okwi, Johannes G. Hoogeveen, Thomas Emwanu, Vincent Linderhof and John Begumana

Figure A5: Sub-county poverty rates, 1992

\section{Uganda 1992: Sub-County Poverty incidence}

\section{Percent of rural poor below poverty line}

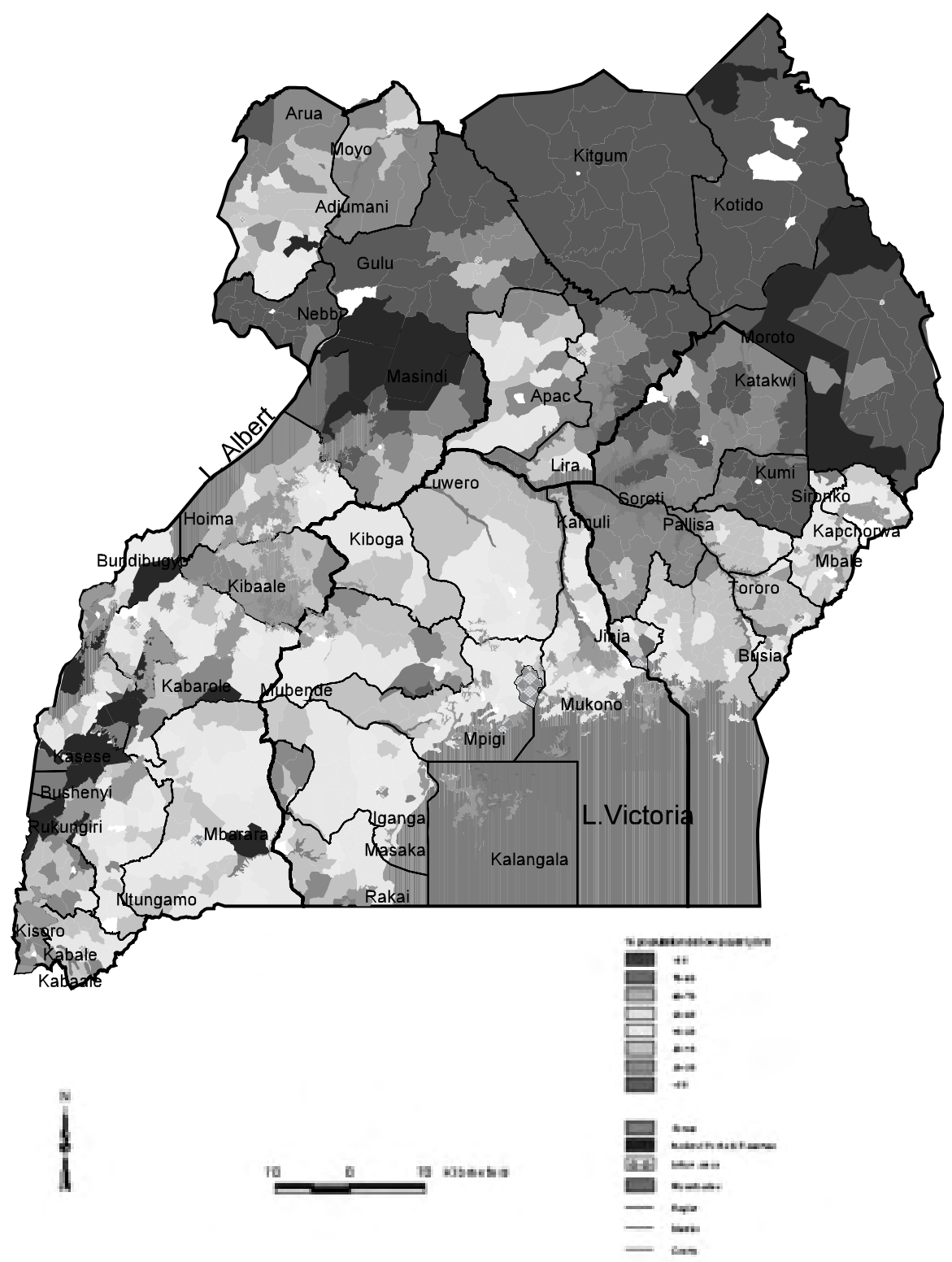




\section{Appendix B: First stage regressions \\ Table B1. First stage regression results for Central region}

\begin{tabular}{|c|c|c|}
\hline \multicolumn{3}{|l|}{ Dependent Variable: log of per capita consumption expenditure } \\
\hline Number of observations:- & \multicolumn{2}{|l|}{1660} \\
\hline Number of Clusters: & \multicolumn{2}{|l|}{163} \\
\hline Adjusted R2: & \multicolumn{2}{|l|}{0.35} \\
\hline Variable & $\begin{array}{l}\text { Parameter } \\
\text { estimate }\end{array}$ & $\begin{array}{l}\text { Standard } \\
\text { error }\end{array}$ \\
\hline Intercept & 10.326 & 0.138 \\
\hline Number of females aged 6-14 & 0.037 & 0.017 \\
\hline Household size squared & 0.001 & 0.000 \\
\hline Logarithm of household size & -0.382 & 0.029 \\
\hline Proportion of males with secondary school & 0.872 & 0.150 \\
\hline Proportion of males without education & -0.153 & 0.046 \\
\hline Proportion of males with education at A 'level & 0.426 & 0.136 \\
\hline Age of household head squared & 0.000 & 0.000 \\
\hline Mean years of education head squared & -0.005 & 0.001 \\
\hline Number of females aged 45 or older & -0.056 & 0.025 \\
\hline Buffer zone within $1 \mathrm{~km}$ of main road & 0.341 & 0.078 \\
\hline Buffer zone within $2 \mathrm{~km}$ of track road & -0.402 & 0.116 \\
\hline Buffer zone within $4 \mathrm{~km}$ of track road & -0.304 & 0.052 \\
\hline Proportion of woodland (parish) & 0.380 & 0.144 \\
\hline Logarithm of age of household head*Alur tribe & 0.929 & 0.267 \\
\hline Logarithm of age of household head *Toro tribe & 2.670 & 0.423 \\
\hline Logarithm of age of household head *Lugbara tribe & 0.422 & 0.183 \\
\hline Logarithm of age of household head * Males aged 30 or older & -0.213 & 0.036 \\
\hline Logarithm of age of household head * Males aged 30 or younger & 0.081 & 0.012 \\
\hline Logarithm of age of household head *Kitchen shared & 0.703 & 0.198 \\
\hline Max. numbers of years of education ${ }^{*}$ Ganda tribe & 0.022 & 0.006 \\
\hline Log. of age of household head *Prop. of females aged 0-5 squared & -2.399 & 0.626 \\
\hline Logarithm of age of household head * Mubende district & -0.062 & 0.013 \\
\hline Log of age of household head * Prop. of subsistent farming (parish) & 0.083 & 0.020 \\
\hline Log of age of household head * Prop. of commercial farming (parish) & 0.183 & 0.058 \\
\hline Log of age of household head *Prop. of water (parish) & 0.057 & 0.026 \\
\hline Mean number of years of education of adults * Buffer within $5 \mathrm{~km}$ of tarmac road & -0.026 & 0.009 \\
\hline Mean number of years of education of adults * Prop. of commercial farming & -0.346 & 0.103 \\
\hline Proportion of males with A'level education*Kiboga district & -0.300 & 0.126 \\
\hline Number of males with education at level P5-P7*Prop. of grassland & 0.188 & 0.047 \\
\hline Male hh. head separated or divorced * Number of males aged 30 or younger & -3.089 & 1.353 \\
\hline Hh. head with education at P5-P7 level * Prop. of town (parish) & 2.999 & 0.766 \\
\hline Hh. head with education at P5-P7 level * Prop. of degraded THF & 1.004 & 0.249 \\
\hline Number of males aged 30 or younger ${ }^{*}$ Mpigi district & -0.050 & 0.014 \\
\hline Japadhola tribe & -2.278 & 0.556 \\
\hline Mugwere tribe & 5.369 & 1.371 \\
\hline
\end{tabular}




\section{Table B2. First stage regression results for the Eastern region}

\begin{tabular}{|c|c|c|}
\hline \multicolumn{3}{|l|}{ Dependent Variable: log of per capita consumption expenditure } \\
\hline Number of observations: & \multicolumn{2}{|l|}{1640} \\
\hline Number of Clusters: & \multicolumn{2}{|l|}{165} \\
\hline Adjusted $\mathrm{R}^{2}$ & \multicolumn{2}{|l|}{0.36} \\
\hline Variable & \begin{tabular}{|l|}
$\begin{array}{l}\text { Parameter } \\
\text { estimate }\end{array}$ \\
\end{tabular} & Standard error \\
\hline Intercept & 9.379 & 0.142 \\
\hline Household size $=10$ & -0.152 & 0.073 \\
\hline Logarithm of adult equivalent size & -0.444 & 0.024 \\
\hline Prop. of males with no secondary education squared & 0.437 & 0.139 \\
\hline Number of males aged $15-29$ years & -0.061 & 0.018 \\
\hline Age of household head squared & 0.000 & 0.000 \\
\hline Prop. of persons with education under A' level & 0.457 & 0.115 \\
\hline Proportion of males with education years 1 to 4 Squared & 0.241 & 0.061 \\
\hline Buffer zone within $1 \mathrm{~km}$ tarmac road & -0.255 & 0.105 \\
\hline Prop. of degraded tropical high forest (parish) & 6.927 & 1.197 \\
\hline Prop. of commercial farm land (parish) & 4.100 & 0.706 \\
\hline Prop. of males with secondary education * Teso tribe & 0.229 & 0.042 \\
\hline Number of males with education between $\mathrm{P} 5-\mathrm{P} 7^{*}$ Ganda tribe & 2.535 & 0.521 \\
\hline Maximum years of education ${ }^{*}$ Rwanda tribe & -1.886 & 0.650 \\
\hline Heads education between P5-P7*Ganda tribe & -2.824 & 1.261 \\
\hline Log of age of household head *Kamuli district & -0.069 & 0.016 \\
\hline Log of age of household head * Kapchorwa district & 0.093 & 0.021 \\
\hline Log of age of household head * Kumi district & -0.070 & 0.015 \\
\hline Log of age of household head *Soroti district & -0.070 & 0.014 \\
\hline Maximum years of education ${ }^{*}$ pit latrine & -0.070 & 0.005 \\
\hline Maximum years of education *Kamuli district & -0.070 & 0.008 \\
\hline Number of males education between $\mathrm{P} 5-\mathrm{P} 7^{*}$ Iganga district & 0.062 & 0.021 \\
\hline Number of males education between P5-P7*buffer within $1 \mathrm{~km}$ track & 0.049 & 0.021 \\
\hline Male hh. head separated, divorcedKamuli district & -0.348 & 0.131 \\
\hline Number of males aged 30 or younger ${ }^{\star}$ Prop. Of woodlot & 1.220 & 0.303 \\
\hline Number of males aged 30-49 (EA mean ) & 0.584 & 0.184 \\
\hline Household size $=1$ & 1.722 & 0.281 \\
\hline Household size $=8$ & 1.587 & 0.546 \\
\hline Number of females aged younger than 10 (EA mean) & -0.692 & 0.266 \\
\hline Number of females aged 6-14 (EA mean) & -1.449 & 0.235 \\
\hline Number of females aged younger than 15 (EA mean) & 1.112 & 0.288 \\
\hline Number of males with education P1-P4 years (EA mean) & 0.444 & 0.105 \\
\hline Number of males with education $\mathrm{P} 1-\mathrm{P} 4$ years squared (EA mean) & -1.904 & 0.738 \\
\hline
\end{tabular}


Table B3. First stage regression results for the Northern region

\begin{tabular}{|c|c|c|}
\hline \multicolumn{3}{|l|}{ Dependent Variable: log of per capita consumption expenditure } \\
\hline Number of observations: & \multicolumn{2}{|l|}{1368} \\
\hline Number of Clusters: & \multicolumn{2}{|l|}{144} \\
\hline Adjusted $\mathrm{R}^{2}$ & \multicolumn{2}{|l|}{0.46} \\
\hline Variable & \begin{tabular}{|l|} 
Parameter \\
estimate
\end{tabular} & Standard error \\
\hline Intercept & 10.225 & 0.093 \\
\hline Number of males with at least secondary school & 0.061 & 0.029 \\
\hline Household size $=5$ & 0.090 & 0.036 \\
\hline Household size $=13$ & 0.366 & 0.121 \\
\hline Maximum years of education 13 squared & -0.001 & 0.000 \\
\hline Log of adult equivalent size & -0.681 & 0.052 \\
\hline Proportion of females aged 30-49 squared & 0.350 & 0.141 \\
\hline Number of males with education years 1 to 4 & -0.083 & 0.019 \\
\hline Number of males with primary education & 0.101 & 0.016 \\
\hline Proportion of males with education O'level and above & 0.512 & 0.179 \\
\hline Number of females aged 30 or older & 0.092 & 0.026 \\
\hline Buffer zone within $1 \mathrm{~km}$ from main road (parish) & 0.682 & 0.233 \\
\hline Buffer zone within $1 \mathrm{~km}$ from tarmac road (parish) & 6.153 & 1.623 \\
\hline Buffer zone within $3 \mathrm{~km}$ from tarmac road (parish) & -8.865 & 1.692 \\
\hline Buffer zone within $4 \mathrm{~km}$ from tarmac road (parish) & 5.732 & 0.969 \\
\hline Proportion of subsistence farmland (parish) & -0.130 & 0.054 \\
\hline Proportion of wet subsistence farmland (parish) & -3.714 & 1.160 \\
\hline Proportion of water (parish) & 0.856 & 0.140 \\
\hline Age of household head age ${ }^{*}$ tribe Lugbar & 0.007 & 0.002 \\
\hline Age of household head age ${ }^{*}$ district Arua & 0.008 & 0.002 \\
\hline Meal hh. head separated or divorced squared & 2.866 & 1.169 \\
\hline Maximum years of education* tribe Madi & 0.057 & 0.008 \\
\hline Number of males aged 30 and above* district Arua & -0.143 & 0.051 \\
\hline Number of males aged 50 and above * Head male separated divorced & -0.406 & 0.106 \\
\hline Number of males aged 50 and above*tribe Lugbar & -0.569 & 0.114 \\
\hline Number of females aged 15 and below* district Apac & 0.066 & 0.012 \\
\hline Age of Household head ${ }^{*}$ Proportion of parish within $1 \mathrm{~km}$ from main road & -0.020 & 0.004 \\
\hline Log of adult equivalent size * Distric Gulu & -0.346 & 0.087 \\
\hline Log of adult equivalent size * Prop. of parish within $1 \mathrm{~km}$ from main road & 0.253 & 0.115 \\
\hline Log of adult equivalent size * Prop. of parish within $1 \mathrm{~km}$ from track road & 0.105 & 0.047 \\
\hline Head males separated divorced * district Gulu & 0.564 & 0.233 \\
\hline Head males separated divorced * district Kitgum & -0.445 & 0.176 \\
\hline Head males separated divorced * district Nebbi & -3.059 & 1.076 \\
\hline
\end{tabular}




\begin{tabular}{l|ll}
\hline Maximum years of education * district Gulu & 0.059 & 0.011 \\
Maximum years of education* district Lira & 0.015 & 0.005 \\
Maximum years of education* district Moroto & 0.106 & 0.041 \\
Maximum years of education is 13 years* district Gulu & 0.025 & 0.012 \\
Number of males aged 30 and above* district Moyo & -0.177 & 0.063 \\
Number of males aged 50 or older *Main road buffer zone of 1 km & 0.609 & 0.133 \\
Proportion of females aged 0-5 squared (EA mean) & -4.514 & 1.140 \\
Proportion of females aged 45 plus (EA mean) & -0.599 & 0.134 \\
\hline
\end{tabular}




\section{Table B4. First stage regression results for the Western region}

\begin{tabular}{|c|c|c|}
\hline \multicolumn{3}{|l|}{ Dependent Variable: log of per capita consumption expenditure } \\
\hline Number of observations: & \multicolumn{2}{|l|}{1637} \\
\hline Number of Clusters: & \multicolumn{2}{|l|}{163} \\
\hline Adjusted $\mathrm{R}^{2}$ & \multicolumn{2}{|l|}{0.34} \\
\hline Variable & $\begin{array}{l}\text { Parameter } \\
\text { estimate }\end{array}$ & Standard error \\
\hline Intercept & 10.391 & 0.111 \\
\hline Number of females aged 6-14 & 0.047 & 0.017 \\
\hline Number of males with education above O'level & 0.079 & 0.037 \\
\hline Household size squared & 0.004 & 0.001 \\
\hline Household size $=11$ & -0.343 & 0.101 \\
\hline Log of household size & -0.246 & 0.041 \\
\hline Proportion of females aged $0-5$ squared & 0.934 & 0.235 \\
\hline Proportion of females aged 30-49 squared & 0.451 & 0.129 \\
\hline Number of males with no education & -0.077 & 0.013 \\
\hline Number of males with education 1 to 4 years & -0.076 & 0.016 \\
\hline Age of Household head squared & 0.000 & 0.000 \\
\hline Proportion of parish within $1 \mathrm{~km}$ from track road & 0.975 & 0.165 \\
\hline Proportion of parish within $2 \mathrm{~km}$ from track road & -0.684 & 0.145 \\
\hline Proportion of parish within $3 \mathrm{~km}$ from tarmac road & 0.169 & 0.049 \\
\hline Proportion of parish within $4 \mathrm{~km}$ from track road & 0.226 & 0.066 \\
\hline Proportion of parish under woodlot & -6.715 & 2.067 \\
\hline Proportion of parish under subsistence farmland & -0.240 & 0.053 \\
\hline Proportion of parish under wet subsistence farmland & 1.096 & 0.300 \\
\hline Log of household heads age ${ }^{*}$ tribe Kiga & 0.034 & 0.013 \\
\hline Log of household heads age ${ }^{*}$ tribe Konjo & 0.206 & 0.028 \\
\hline Log of household heads age * tribe Nkole & 0.107 & 0.013 \\
\hline Mean education years $=18^{*}$ tribe Alur & 0.216 & 0.082 \\
\hline Mean education years $=18^{*}$ tribe Nkole & -0.023 & 0.011 \\
\hline Mean education years $=18^{*}$ tribe Nyoro & -0.083 & 0.018 \\
\hline Head no education* tribe Alur & -1.828 & 0.560 \\
\hline Head male separated divorced tribe Konjo; & 0.574 & 0.250 \\
\hline Maximum years of education * tribe Alur; & -0.230 & 0.062 \\
\hline Maximum years of education*tribe Ganda; & 0.231 & 0.077 \\
\hline Log of household heads age*district Hoima; & 0.071 & 0.018 \\
\hline Log of household heads age ${ }^{*}$ district Kasese; & -0.134 & 0.029 \\
\hline Mean education years $18^{*}$ Proportion of parish under towns & -1.815 & 0.881 \\
\hline Head no education * district Kabarole; & -0.157 & 0.052 \\
\hline Proportion of males with no education ${ }^{*}$ prop.of parish under towns & -11.510 & 4.072 \\
\hline Head males separated divorced* district Hoima; & 0.478 & 0.198 \\
\hline Household size $=6^{*}$ district Kabarole; & 0.348 & 0.098 \\
\hline Household size $=6^{*}$ district Kabale; & 0.367 & 0.127 \\
\hline Number of males with education above O'level (EA mean) & 0.840 & 0.172 \\
\hline Number of females aged 35 or older (EA mean) & -0.419 & 0.096 \\
\hline
\end{tabular}


Appendix C: Poverty estimates at district level

Table C1. Rural Strata: District Mean Per capita Expenditure, Poverty and Inequality Estimates

\begin{tabular}{|c|c|c|c|c|c|c|}
\hline Code & District & Population & Mean Y & FGTO & FGT1 & FGT2 \\
\hline \multicolumn{7}{|c|}{ Central } \\
\hline \multirow[t]{2}{*}{11} & Kalangala & 14,079 & 26452.51 & 25.09 & 6.21 & 2.25 \\
\hline & & & (2198.34) & $(0.05)$ & $(0.02)$ & $(0.01)$ \\
\hline \multirow[t]{2}{*}{17} & Kiboga & 131,445 & 15858.74 & 62.11 & 22.20 & 10.43 \\
\hline & & & (756.16) & (0.03) & $(0.02)$ & $(0.01)$ \\
\hline \multirow[t]{2}{*}{23} & Luwero & 403,948 & 17501.48 & 55.45 & 18.41 & 8.21 \\
\hline & & & (527.67) & $(0.02)$ & $(0.01)$ & $(0.01)$ \\
\hline \multirow[t]{2}{*}{24} & Masaka & 723,415 & 18651.63 & 50.34 & 15.77 & 6.74 \\
\hline & & & (558.90) & $(0.02)$ & $(0.01)$ & $(0.00)$ \\
\hline \multirow[t]{2}{*}{30} & Mpigi & 761,066 & 19671.96 & 48.82 & 15.91 & 7.05 \\
\hline & & & (722.53) & $(0.03)$ & $(0.01)$ & $(0.01)$ \\
\hline \multirow[t]{2}{*}{31} & Mubende & 445,077 & 16176.08 & 63.00 & 23.20 & 11.10 \\
\hline & & & (888.90) & $(0.03)$ & $(0.02)$ & $(0.01)$ \\
\hline \multirow[t]{2}{*}{32} & Mukono & 705,227 & 19077.89 & 49.45 & 15.94 & 7.01 \\
\hline & & & (674.38) & (0.02) & $(0.01)$ & $(0.01)$ \\
\hline \multirow[t]{2}{*}{35} & Rakai & 361,501 & 16312.77 & 60.87 & 21.49 & 9.99 \\
\hline & & & (563.14) & (0.02) & $(0.01)$ & $(0.01)$ \\
\hline \multicolumn{7}{|l|}{ East } \\
\hline \multirow[t]{2}{*}{7} & Iganga & 885,398 & 23364.78 & 58.38 & 20.59 & 9.58 \\
\hline & & & (8399.97) & $(2.24)$ & $(1.24)$ & (0.75) \\
\hline \multirow[t]{2}{*}{8} & Jinja & 203,021 & 65272.74 & 39.53 & 12.38 & 5.35 \\
\hline & & & (54955.40) & (3.37) & $(1.36)$ & (0.69) \\
\hline \multirow[t]{2}{*}{13} & Kamuli & 460,682 & 12789.89 & 73.89 & 30.62 & 15.93 \\
\hline & & & (835.61) & (3.68) & $(2.96)$ & (2.07) \\
\hline \multirow[t]{2}{*}{14} & Kapchorwa & 102,019 & 19059.53 & 45.81 & 13.73 & 5.71 \\
\hline & & & (1677.03) & (6.31) & $(2.70)$ & (1.37) \\
\hline \multirow[t]{2}{*}{21} & Kumi & 216,150 & 10945.13 & 82.40 & 37.00 & 20.20 \\
\hline & & & (776.46) & (3.37) & (3.16) & (2.34) \\
\hline \multirow[t]{2}{*}{26} & Mbale & 640,929 & 16205.49 & 58.85 & 20.51 & 9.49 \\
\hline & & & (545.66) & $(2.26)$ & (1.29) & $(0.78)$ \\
\hline \multirow[t]{2}{*}{34} & Pallisa & 347,936 & 14909.63 & 63.66 & 23.01 & 10.90 \\
\hline & & & (485.59) & $(2.15)$ & $(1.29)$ & (0.81) \\
\hline \multirow[t]{2}{*}{37} & Soroti & 358,452 & 11741.12 & 78.66 & 34.09 & 18.22 \\
\hline & & & (742.83) & (3.33) & $(2.76)$ & (1.96) \\
\hline \multirow[t]{2}{*}{38} & Tororo & 483,104 & 17926.81 & 62.84 & 22.84 & 10.83 \\
\hline & & & (1933.28) & $(2.00)$ & $(1.28)$ & (0.82) \\
\hline
\end{tabular}


Table C2. Rural Strata: District Mean Per capita Expenditure, Poverty and Inequality Estimates

\begin{tabular}{|c|c|c|c|c|c|c|}
\hline Code & District & Population & Mean $Y$ & FGTO & FGT1 & FGT2 \\
\hline \multicolumn{7}{|l|}{ North } \\
\hline \multirow[t]{2}{*}{1} & Apac & 440,829 & 15661.78 & 64.34 & 23.61 & 11.33 \\
\hline & & & (790.82) & $(2.91)$ & $(1.64)$ & (1.01) \\
\hline \multirow[t]{2}{*}{2} & Arua & 600,141 & 16778.39 & 64.01 & 23.21 & 11.00 \\
\hline & & & (862.38) & (2.93) & $(1.80)$ & (1.10) \\
\hline \multirow[t]{2}{*}{5} & Gulu & 277,223 & 12081.47 & 79.77 & 38.53 & 22.21 \\
\hline & & & $(652.15)$ & (1.96) & $(2.02)$ & (1.65) \\
\hline \multirow[t]{2}{*}{19} & Kitgum & 327,085 & 13140.80 & 88.21 & 41.92 & 23.45 \\
\hline & & & (30480.45) & (1.29) & $(1.54)$ & (1.24) \\
\hline \multirow[t]{2}{*}{20} & Kotido & 111,552 & 8817.79 & 90.90 & 47.29 & 28.30 \\
\hline & & & (424.99) & (1.39) & $(2.13)$ & (1.89) \\
\hline \multirow[t]{2}{*}{22} & Lira & 454,193 & 13526.99 & 73.46 & 29.95 & 15.34 \\
\hline & & & $(577.26)$ & (2.35) & $(1.77)$ & (1.22) \\
\hline \multirow[t]{2}{*}{28} & Moroto & 123,002 & 11349.58 & 83.74 & 42.62 & 25.44 \\
\hline & & & (1609.66) & (2.67) & $(2.20)$ & (1.74) \\
\hline \multirow[t]{2}{*}{29} & Moyo & 132,801 & 13994.23 & 70.20 & 28.16 & 14.36 \\
\hline & & & $(664.04)$ & $(2.75)$ & $(1.84)$ & (1.23) \\
\hline \multirow[t]{2}{*}{33} & Nebbi & 286,352 & 10019.24 & 87.93 & 40.72 & 22.27 \\
\hline & & & $(327.17)$ & $(1.32)$ & (1.58) & $(1.27)$ \\
\hline \multicolumn{7}{|l|}{ West } \\
\hline \multirow[t]{2}{*}{3} & Bundibugyo & 103,236 & 16035.53 & 57.82 & 23.14 & 12.22 \\
\hline & & & (1100.32) & (3.88) & $(2.51)$ & (1.72) \\
\hline \multirow[t]{2}{*}{4} & Bushenyi & 711,713 & 18688.97 & 44.60 & 14.71 & 6.89 \\
\hline & & & (753.93) & $(2.97)$ & $(1.31)$ & $(0.71)$ \\
\hline \multirow[t]{2}{*}{6} & Hoima & 188,347 & 17334.30 & 52.34 & 19.01 & 9.48 \\
\hline & & & (1452.48) & (5.87) & $(2.97)$ & (1.74) \\
\hline \multirow[t]{2}{*}{9} & Kabale & 382,099 & 15746.15 & 55.93 & 19.74 & 9.60 \\
\hline & & & (858.46) & $(4.05)$ & $(2.01)$ & (1.15) \\
\hline \multirow[t]{2}{*}{10} & Kabarole & 693,706 & 16887.08 & 51.31 & 17.82 & 8.60 \\
\hline & & & $(704.22)$ & (3.00) & $(1.43)$ & (0.81) \\
\hline \multirow[t]{2}{*}{15} & Kasese & 294,155 & 15962.43 & 55.47 & 19.69 & 9.62 \\
\hline & & & (1314.83) & (6.27) & (3.25) & (1.88) \\
\hline \multirow[t]{2}{*}{16} & Kibaale & 212,124 & 13310.58 & 68.60 & 26.68 & 13.71 \\
\hline & & & $(614.08)$ & (3.11) & $(2.12)$ & (1.38) \\
\hline \multirow[t]{2}{*}{18} & Kisoro & 176,360 & 12929.51 & 70.26 & 27.33 & 14.03 \\
\hline & & & $(749.21)$ & $(4.07)$ & $(2.68)$ & (1.71) \\
\hline \multirow[t]{2}{*}{25} & Masindi & 225,504 & 11852.71 & 76.20 & 33.58 & 18.74 \\
\hline & & & (879.23) & (3.91) & (3.37) & (2.51) \\
\hline \multirow[t]{2}{*}{27} & Mbarara & 865,415 & 19429.69 & 42.49 & 13.87 & 6.45 \\
\hline & & & $(749.62)$ & (2.53) & $(1.06)$ & (0.56) \\
\hline \multirow[t]{2}{*}{36} & Rukungiri & 371,360 & 13854.28 & 65.35 & 24.11 & 11.99 \\
\hline & & & (594.17) & (3.17) & $(1.78)$ & (1.07) \\
\hline
\end{tabular}


Paul Okiira Okwi, Johannes G. Hoogeveen, Thomas Emwanu, Vincent Linderhof and John Begumana

\section{Appendix D: Overlays of poverty and biomass}

Figure D1: Map of poverty incidence in Uganda based on the poverty estimates with biomass.

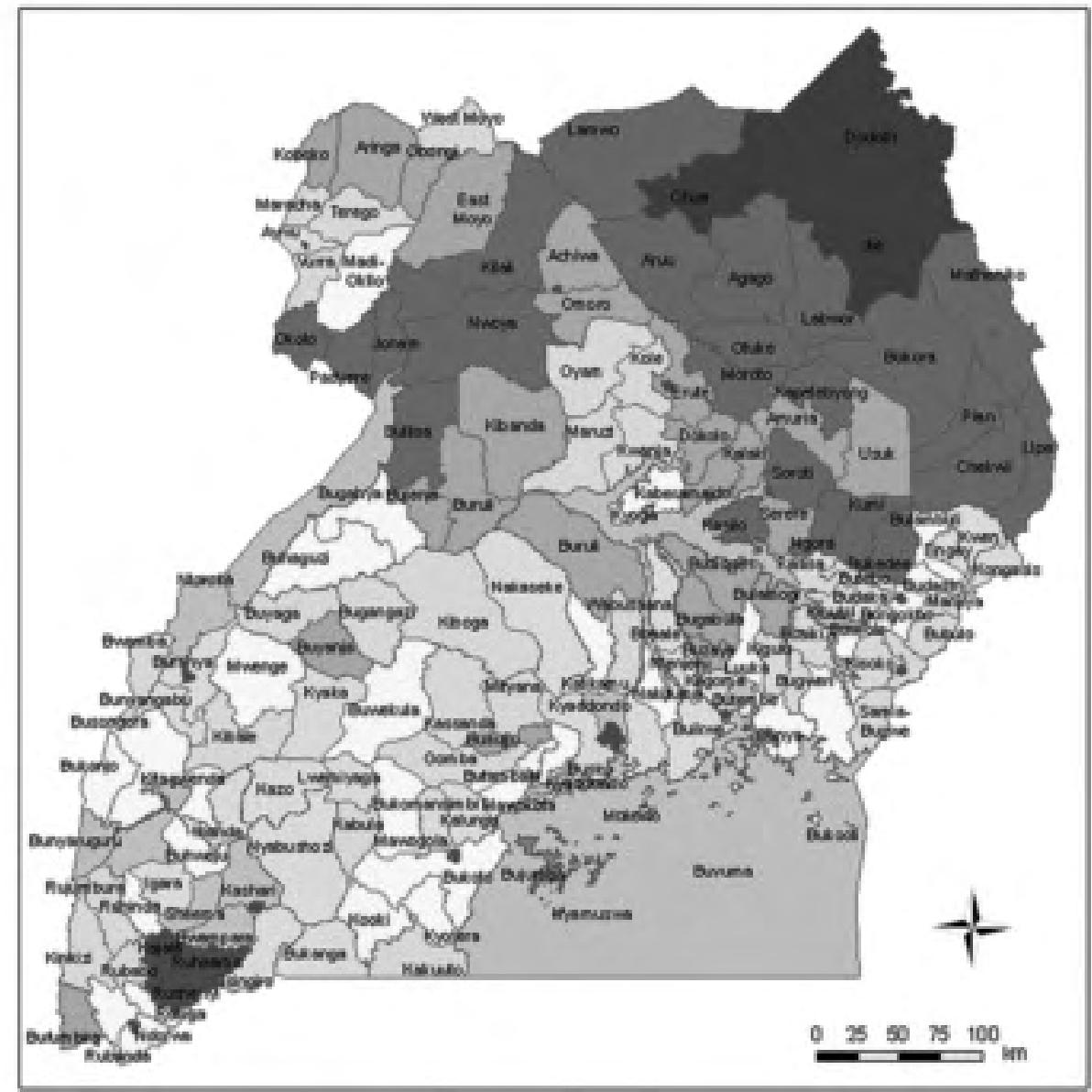

Poverty incidence

\begin{tabular}{|c|c|c|}
\hline $0.20 \%$ & $40.30 \leqslant$ & $70.80 \%$ \\
\hline $20.30 \%$ & 50.60 & $00-90 \%$ \\
\hline $30.0 \%$ & $60.70 \%$ & $x-100 \%$ \\
\hline
\end{tabular}




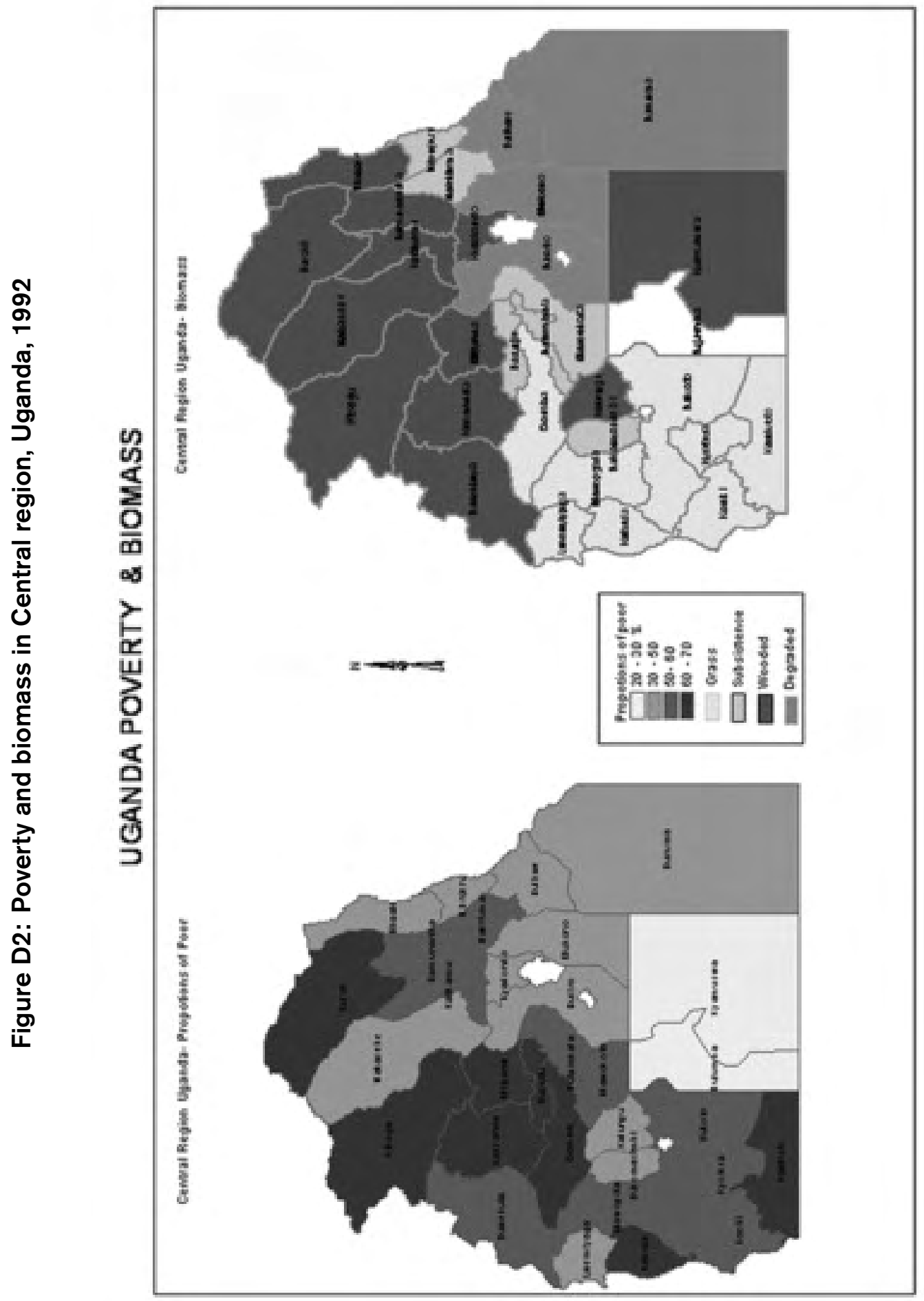




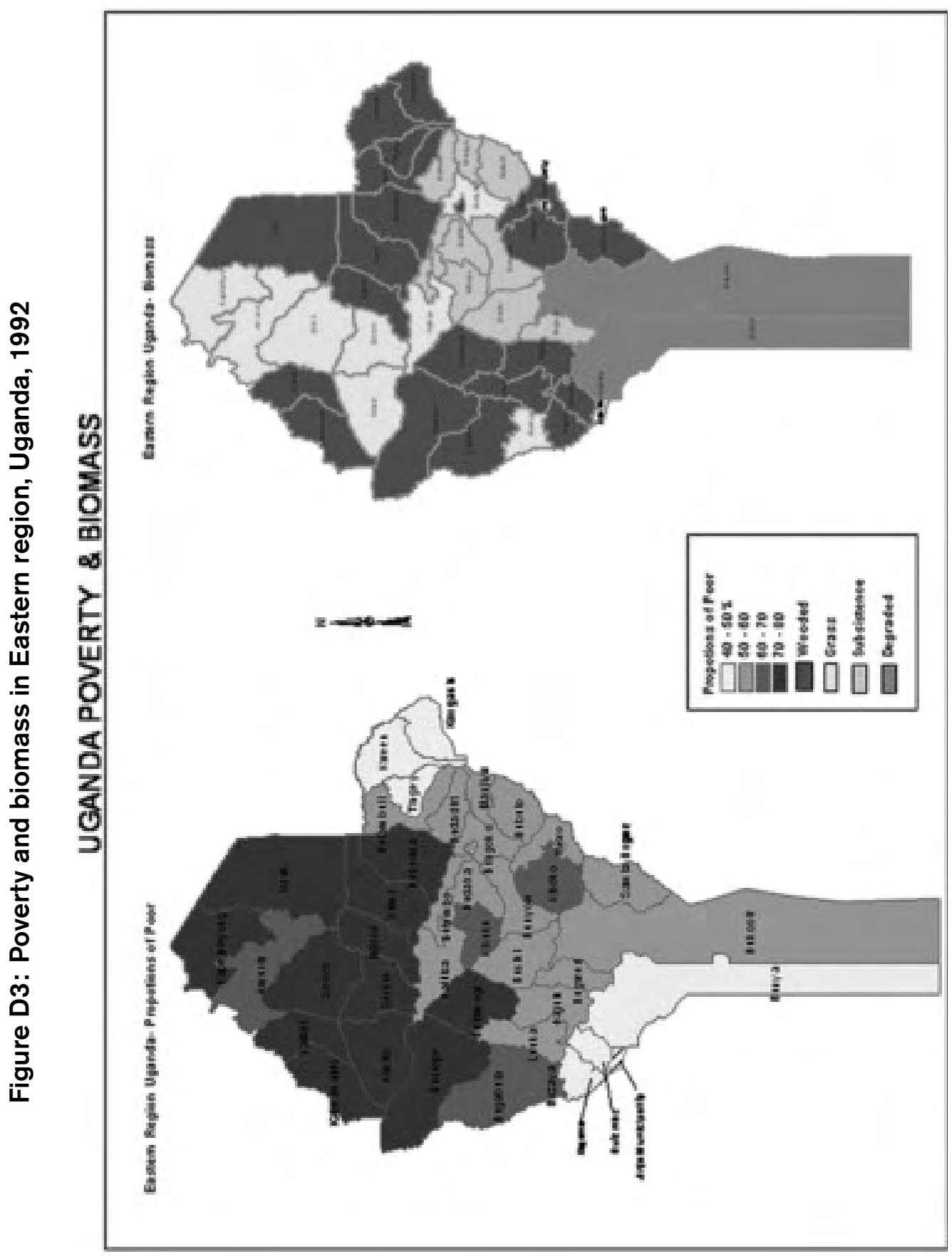




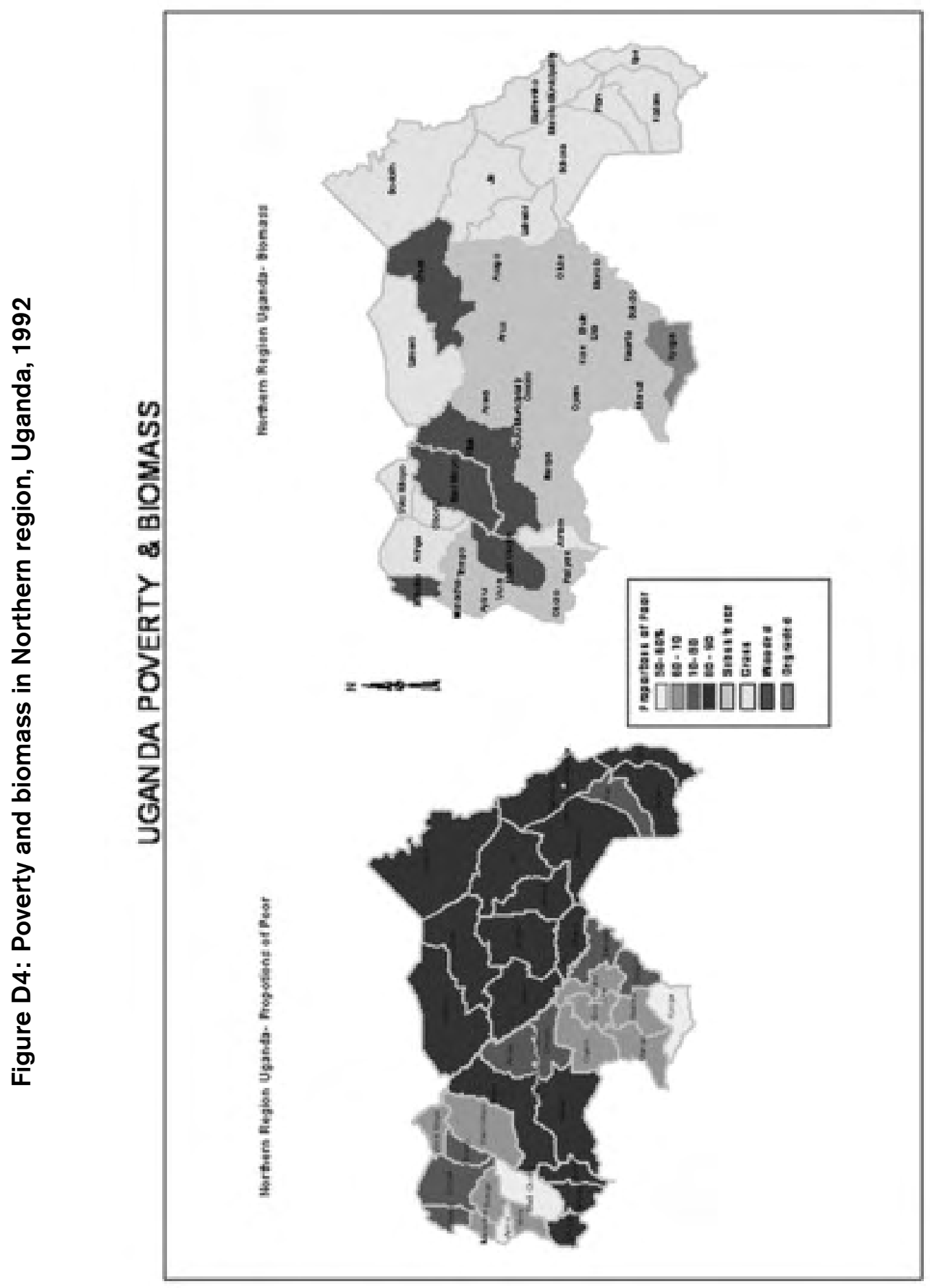




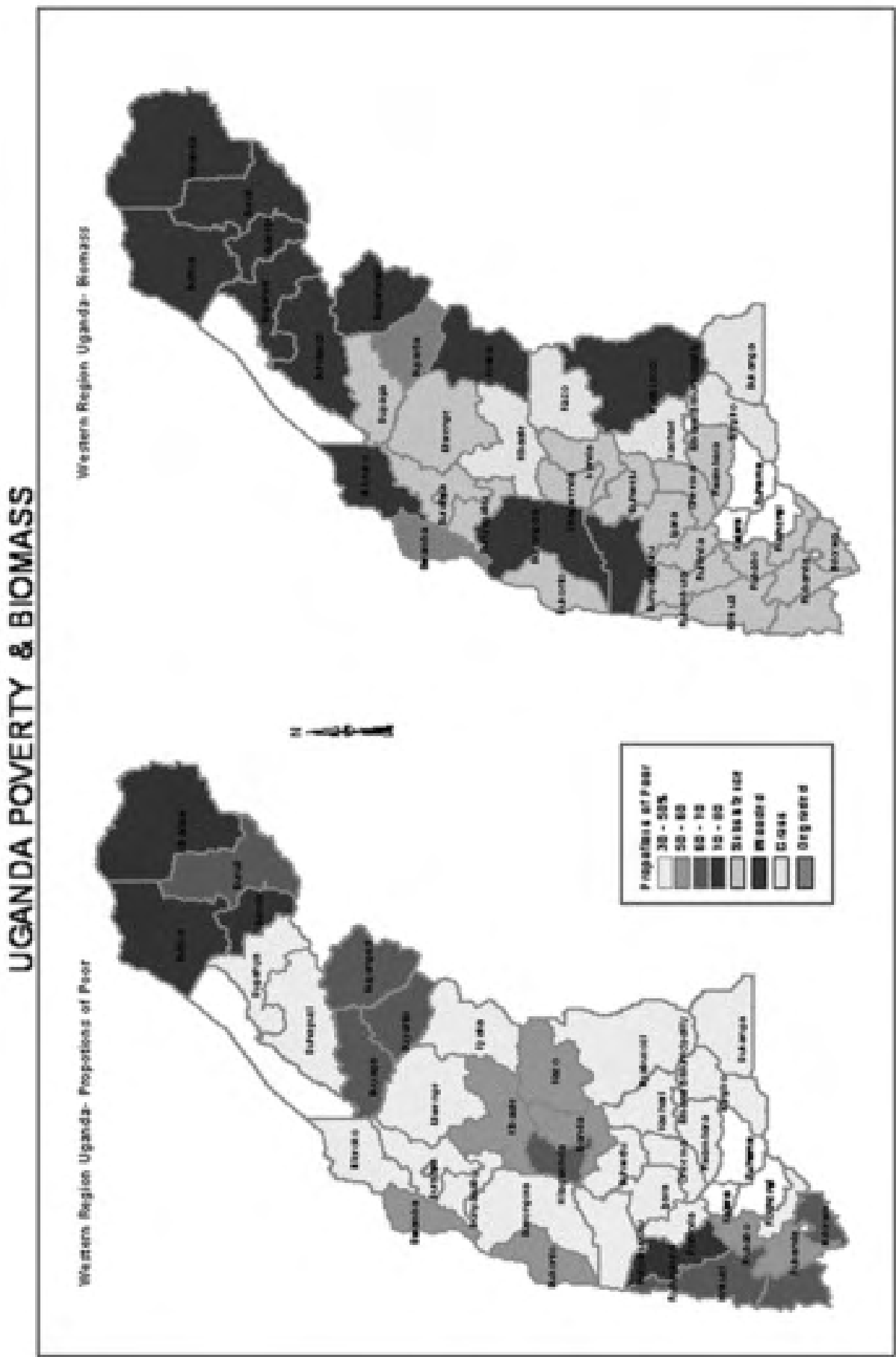


Appendix E: Correlations between biomass and poverty

Table E1: Correlation coefficients between land use (biomass) and poverty incidence* at county level

\begin{tabular}{|c|c|c|c|c|c|}
\hline Biophysical variable & Uganda & Central & East & North & West \\
\hline \multicolumn{6}{|l|}{ Buffer zones of main road } \\
\hline $1 \mathrm{~km}$ & -0.031 & 0.136 & -0.646 & 0.033 & -0.653 \\
\hline $2 \mathrm{~km}$ & -0.011 & 0.172 & -0.662 & 0.027 & -0.650 \\
\hline $3 \mathrm{~km}$ & 0.012 & 0.206 & -0.664 & -0.001 & -0.648 \\
\hline $4 \mathrm{~km}$ & 0.046 & 0.227 & -0.643 & -0.019 & -0.641 \\
\hline $5 \mathrm{~km}$ & 0.085 & 0.232 & -0.604 & -0.030 & -0.627 \\
\hline \multicolumn{6}{|l|}{ Buffer zones of tarmac road } \\
\hline $1 \mathrm{~km}$ & -0.347 & 0.000 & -0.511 & -0.502 & -0.173 \\
\hline $2 \mathrm{~km}$ & -0.337 & 0.045 & -0.507 & -0.506 & -0.220 \\
\hline $3 \mathrm{~km}$ & -0.329 & 0.081 & -0.501 & -0.506 & -0.267 \\
\hline $4 \mathrm{~km}$ & -0.321 & 0.109 & -0.494 & -0.502 & -0.300 \\
\hline $5 \mathrm{~km}$ & -0.315 & 0.133 & -0.491 & -0.498 & -0.324 \\
\hline \multicolumn{6}{|l|}{ Buffer zones of tracks } \\
\hline $1 \mathrm{~km}$ & -0.052 & 0.125 & -0.365 & -0.408 & -0.337 \\
\hline $2 \mathrm{~km}$ & -0.045 & 0.171 & -0.401 & -0.451 & -0.356 \\
\hline $3 \mathrm{~km}$ & -0.019 & 0.200 & -0.409 & -0.474 & -0.363 \\
\hline $4 \mathrm{~km}$ & 0.015 & 0.214 & -0.390 & -0.462 & -0.368 \\
\hline $5 \mathrm{~km}$ & 0.054 & 0.221 & -0.365 & -0.434 & -0.369 \\
\hline \multicolumn{6}{|l|}{ Land use covers } \\
\hline Hardwoods & -0.238 & -0.068 & -0.357 & -0.109 & -0.527 \\
\hline Softwoods & -0.072 & -0.006 & -0.361 & -0.085 & 0.116 \\
\hline Tropical high forest -normal & -0.294 & -0.564 & -0.113 & 0.277 & -0.020 \\
\hline Tropical high forest-depleted & -0.208 & -0.160 & -0.161 & 0.307 & -0.113 \\
\hline Woodlands and bush lands & 0.409 & 0.046 & 0.587 & 0.245 & 0.345 \\
\hline Grasslands & 0.095 & 0.172 & 0.619 & -0.417 & 0.444 \\
\hline Wetlands & -0.026 & 0.172 & -0.071 & -0.154 & -0.080 \\
\hline Subsistent farmland & -0.135 & 0.315 & -0.614 & 0.008 & -0.409 \\
\hline Commercial farmland & -0.224 & -0.103 & -0.428 & 0.124 & -0.424 \\
\hline Subsistent farmland/wetlands\# & -0.069 & -0.025 & -0.429 & 0.305 & -0.064 \\
\hline Built up areas & -0.322 & -0.302 & -0.673 & -0.065 & -0.460 \\
\hline Water & -0.239 & -0.661 & 0.000 & 0.077 & -0.146 \\
\hline
\end{tabular}

* The poverty incidences are derived from Okwi et al. (2003), and therefore are the poverty estimates without biophysical information.

\# Subsistent farmland/wetland is part of the Subsistent farmland. 
Table E2: Correlation coefficients between land use (biomass) and Number of poor people* at county level

\begin{tabular}{|c|c|c|c|c|c|}
\hline Biophysical variable & Uganda & Central & East & North & West \\
\hline \multicolumn{6}{|l|}{ Buffer zones of main road } \\
\hline $1 \mathrm{~km}$ & 0.068 & 0.003 & 0.124 & 0.478 & 0.075 \\
\hline $2 \mathrm{~km}$ & 0.048 & -0.003 & 0.091 & 0.455 & 0.109 \\
\hline $3 \mathrm{~km}$ & 0.029 & -0.014 & 0.053 & 0.442 & 0.146 \\
\hline $4 \mathrm{~km}$ & 0.010 & -0.025 & 0.018 & 0.436 & 0.162 \\
\hline $5 \mathrm{~km}$ & -0.012 & -0.032 & -0.020 & 0.424 & 0.167 \\
\hline \multicolumn{6}{|l|}{ Buffer zones of tarmac road } \\
\hline $1 \mathrm{~km}$ & 0.115 & 0.033 & 0.183 & 0.093 & 0.590 \\
\hline $2 \mathrm{~km}$ & 0.117 & 0.031 & 0.193 & 0.088 & 0.590 \\
\hline $3 \mathrm{~km}$ & 0.124 & 0.034 & 0.206 & 0.090 & 0.575 \\
\hline $4 \mathrm{~km}$ & 0.129 & 0.038 & 0.217 & 0.093 & 0.552 \\
\hline $5 \mathrm{~km}$ & 0.132 & 0.041 & 0.224 & 0.098 & 0.522 \\
\hline \multicolumn{6}{|l|}{ Buffer zones of tracks } \\
\hline $1 \mathrm{~km}$ & 0.071 & 0.062 & 0.241 & 0.101 & 0.280 \\
\hline $2 \mathrm{~km}$ & 0.040 & 0.047 & 0.214 & 0.068 & 0.285 \\
\hline $3 \mathrm{~km}$ & 0.012 & 0.024 & 0.155 & 0.066 & 0.290 \\
\hline $4 \mathrm{~km}$ & -0.014 & 0.001 & 0.088 & 0.047 & 0.303 \\
\hline $5 \mathrm{~km}$ & -0.036 & -0.017 & 0.022 & 0.012 & 0.324 \\
\hline \multicolumn{6}{|l|}{ Land use covers } \\
\hline Hardwoods & 0.037 & 0.239 & -0.023 & 0.393 & -0.060 \\
\hline Softwoods & 0.133 & 0.157 & -0.170 & 0.274 & 0.255 \\
\hline Tropical high forest -normal & -0.098 & -0.335 & 0.383 & -0.024 & -0.050 \\
\hline Tropical high forest -depleted & 0.045 & 0.194 & 0.372 & -0.250 & -0.239 \\
\hline Woodlands and bush lands & -0.259 & -0.242 & -0.381 & -0.322 & -0.295 \\
\hline Grasslands & -0.386 & -0.181 & -0.539 & -0.419 & -0.176 \\
\hline Wetlands & 0.027 & 0.068 & 0.164 & -0.230 & -0.414 \\
\hline Subsistent farmland & 0.381 & 0.448 & 0.279 & 0.577 & 0.460 \\
\hline Commercial farmland & -0.065 & 0.251 & -0.139 & -0.091 & 0.292 \\
\hline Subsistent farmland/wetlands\# & 0.165 & 0.013 & 0.318 & 0.521 & 0.456 \\
\hline Built up areas & 0.144 & 0.179 & 0.103 & 0.245 & 0.081 \\
\hline Water & 0.020 & -0.346 & 0.485 & 0.167 & -0.275 \\
\hline
\end{tabular}

* The poverty incidences are derived from Okwi et al. (2003), and therefore are the poverty estimates wit hout biophysical information.

\# Subsistent farmland/wetland is part of the Subsistent farmland. 
APPENDIX F

Appendix F Comparison of old and new poverty estimates

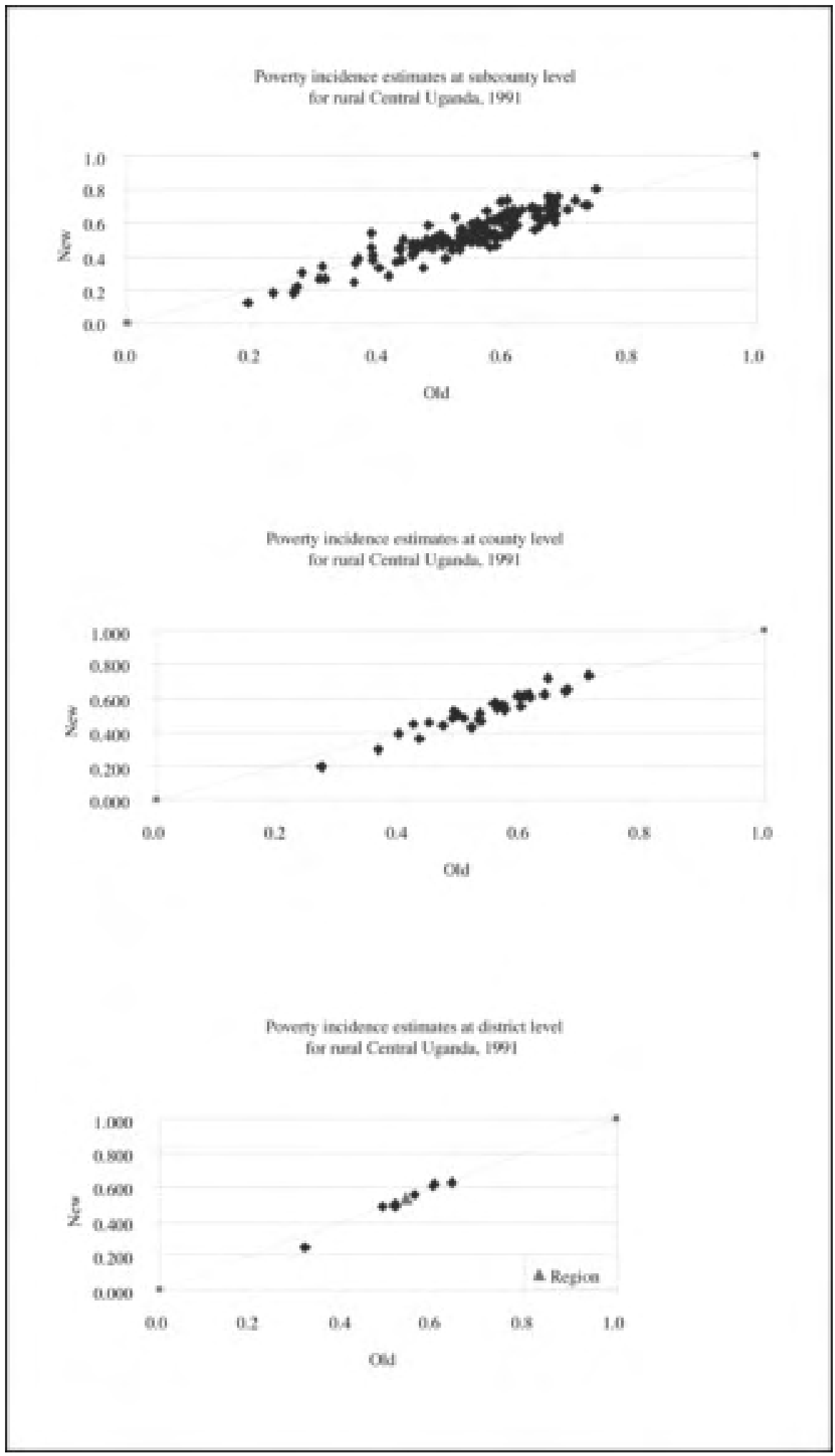


Paul Okiira Okwi, Johannes G. Hoogeveen, Thomas Emwanu, Vincent Linderhof and John Begumana

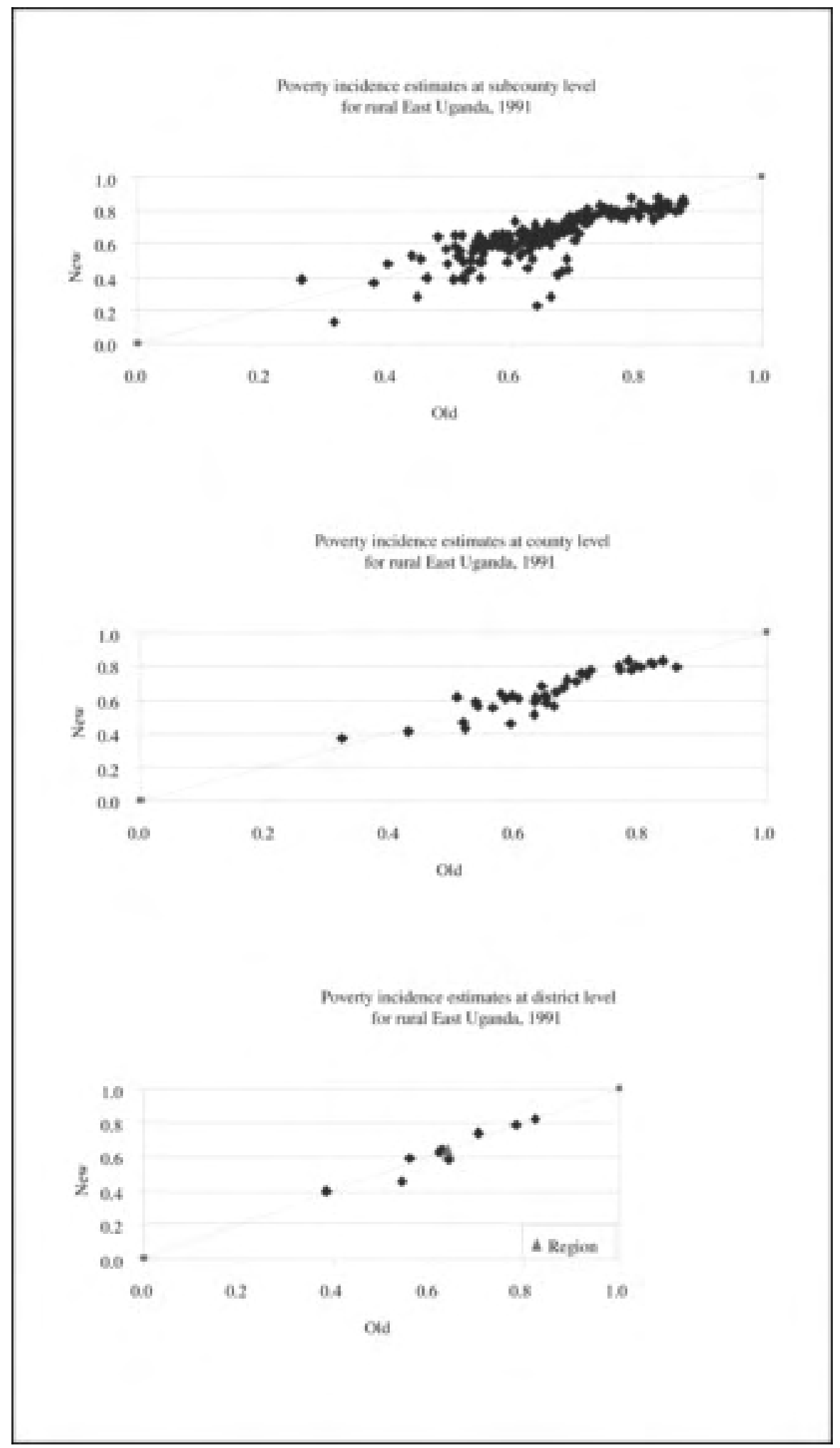




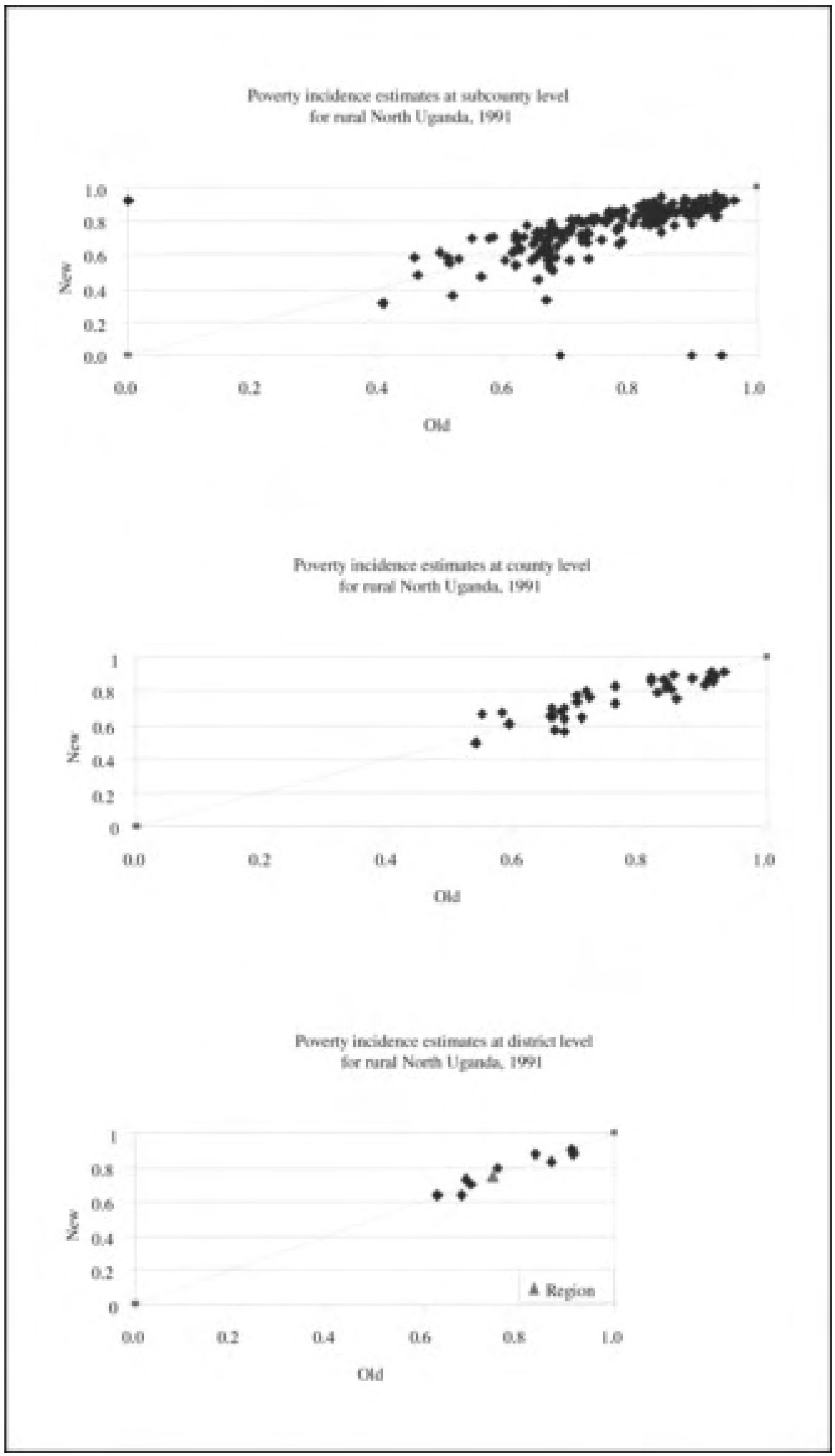


Paul Okiira Okwi, Johannes G. Hoogeveen, Thomas Emwanu, Vincent Linderhof and John Begumana

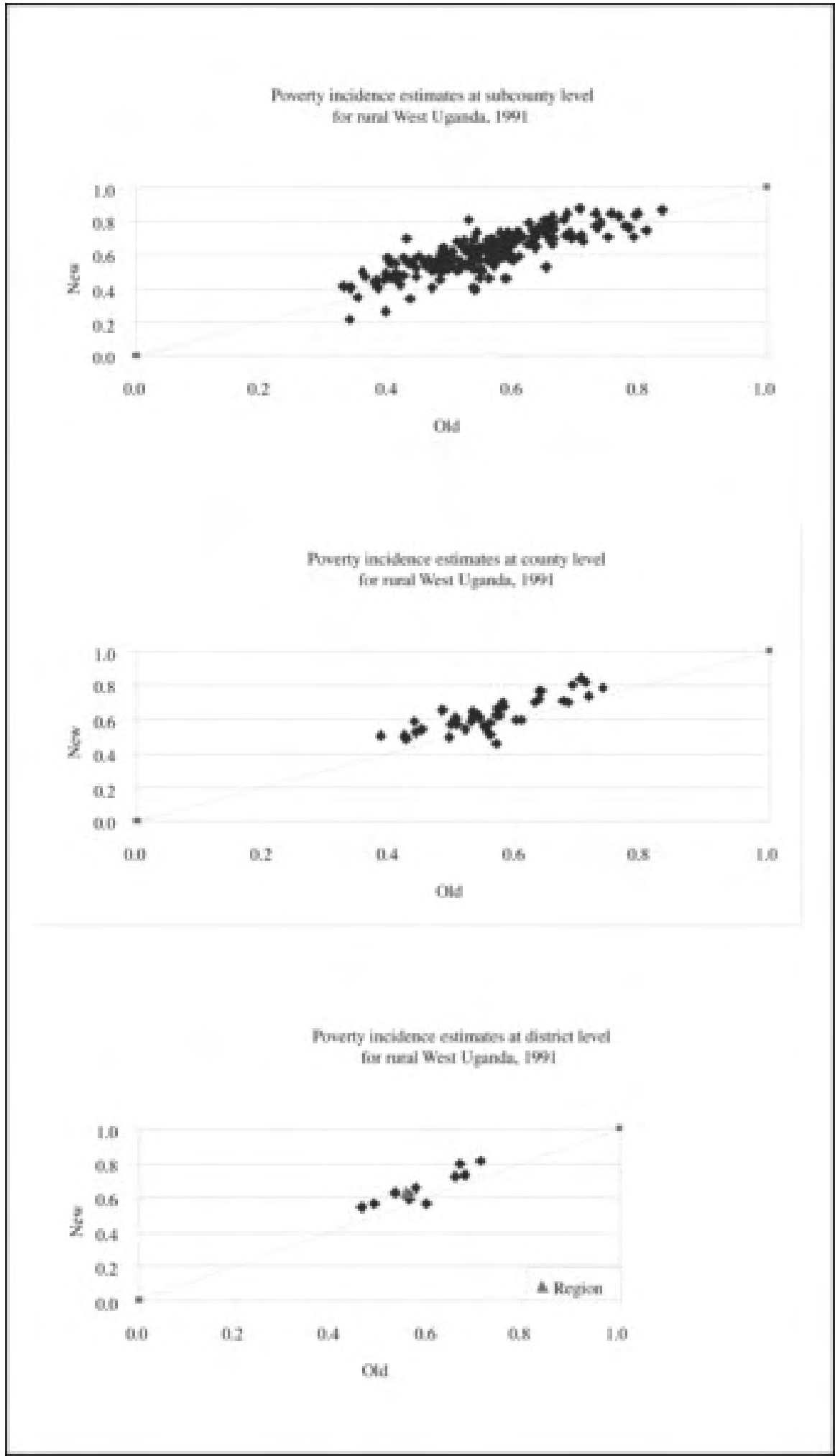

